\title{
Comparison of shear measurements and mixing predictions with a direct observation of diapycnal mixing in the Atlantic thermocline
}

\author{
Timothy F. Duda \\ Applied Ocean Physics and Engineering Department, Woods Hole Oceanographic Institution \\ Woods Hole, Massachusetts \\ David C. Jacobs \\ Scripps Institution of Oceanography, University of California, San Diego, La. Jolla
}

\begin{abstract}
Four sets of velocity and density profiles have been measured with an autonomous profiler during an upper ocean intentional-tracer $\left(\mathrm{SF}_{6}\right)$ diapycnal diffusivity measurement, the North Atlantic Tracer Release Experiment (NATRE). The tracer was injected near $310 \mathrm{~m}$ depth in the Canary Basin. Two profile sets were collected 6 months after tracer release, and two were collected 1 year after release, all within the horizontal boundaries of the $\mathrm{SF}_{6}$ patch. Shear and strain can be combined with turbulent kinetic energy dissipation and diffusivity measurements (published elsewhere) to test existing expressions for dissipation and diffusivity due to shear-induced turbulence. These expressions arise from internal-wave decay modeling. One expression of dissipation parameterized in terms of shear, based on stochastic nonlinear internal-wave interaction, has fared well empirically; its extension to estimate diffusivity is evaluated. Shear variance of the first two data sets was about 1.6 times GM76, and 2.5 to 3.0 times GM76 in the later sets. The average parameterized mixing estimate computed using all of the temporally limited shear measurements overestimates annual mean NATRE diffusivity, $1.5 \times 10^{-5} \mathrm{~m}^{2} \mathrm{~s}^{-1}$, by a factor of 1.2 . A modified parameterization gives an underestimate. To first order, this supports the present understanding of openocean diffusivity in terms of fine-scale shear and internal-wave decay, that is, the slow diapycnal mixing was not a consequence of unusually low shear. Adjustment of the shear-induced mixing models to better fit the data is not warranted because of the lack of direct comparability between the various measurements, the expected natural variability of the shear, and sampling errors.
\end{abstract}

\section{Introduction and NATRE Overview}

The North Atlantic Tracer Release Experiment (NATRE) provided a direct measurement of diapycnal (essentially vertical) mixing over a yearlong period [Ledwell et al., 1993]. The inert compound $\mathrm{SF}_{6}$ was released on a target isopycnal surface at approximately $310 \mathrm{~m}$ depth, and its vertical distribution was surveyed twice; 6 months after release and 1 year after release. The observations robustly indicate vertical mixing rates (eddydiffusivity coefficients $K_{v}$ ) of $1.1 \times 10^{-5} \mathrm{~m}^{2} \mathrm{~s}^{-1}$ for the first period and $1.5 \times 10^{-5} \mathrm{~m}^{2} \mathrm{~s}^{-1}$ for the year.

The observed $K_{v}$ were similar to open-ocean values inferred from dissipation-flux treatment of microstructure measurements in the upper kilometer [Gregg, 1987,

Copyright 1995 by the American Geophysical Union.

Paper number 95JC01023.

0148-0227/95/95JC-01023\$05.00
1989; Gregg and Sanford, 1988; Moum and Osborn, 1986]. These are an order of magnitude smaller than those implied by an advection/diffusion balance in the main thermocline [Garrett, 1993; Munk, 1966] and by budget estimates for the bottoms of ocean basins. To put the NATRE $K_{v}$ values into context, and to show confidence intervals, deep observational budget estimates include $3-4 \times 10^{-4} \mathrm{~m}^{2} \mathrm{~s}^{-1}$ for the deep Brazil Basin [Hogg et al., 1982], $4 \times 10^{-4} \mathrm{~m}^{2} \mathrm{~s}^{-1}$ for the North Atlantic at $2^{\circ} \mathrm{C}$, [Luyten et al., 1993], and $1-4 \times$ $10^{-4} \mathrm{~m}^{2} \mathrm{~s}^{-1}$ for various depths in the deep western North Atlantic [Whitehead, 1987; Whitehead and Worthington, 1982]. Two recent papers review averaged ocean mixing and the possible effects of boundary mixing [Garrett et al., 1993; Toole et al., 1994]. Boundary mixing is a possible explanation of the difference between the observed NATRE $K_{v}$ and the deeper balance estimates, as is a depth dependency of $K_{v}$. Boundary influence on the open-ocean thermocline, where the NATRE $K_{v}$ were recorded, may take the form of sur- 
face ventilation, which adds the complication of air-sea fluxes to the boundary mixing effect.

The breakdown of ocean internal-wave energy into turbulent energy has been accepted as an important mechanism for diapycnal diffusion within the thermocline. It may dominate local mixing activity over much of the ocean interior, although this activity may not be entirely responsible for the stratification equilibrium if boundary mixing plays a role [Armi, 1978; Ivey, 1987]. The likelihood of concentrated energy density and shear, conditioned by the wavenumber-frequency spectrum, has been an enduring candidate as a controlling parameter of the breakdown [Desaubies and Smith, 1982; Munk, 1981]. Two internal-wave dissipation models [Henyey et al., 1986; McComas and Müller, 1981] attempt to quantify energy transfer to high wavenumber, where instability of internal-wave shear is believed to convert wave energy to turbulence. Recent evaluations of a shear/dissipation parameterization derived from the Henyey, Wright, and Flatté (HWF) model have been fairly successful [Gregg, 1989; Gregg and Kunze, 1991]. However, parameterizations derived from the model should be carefully considered because they assume specific internal-wave spectra (derived from Garrett-Munk (GM) [Garrett and Munk, 1972; Gregg and Kunze, 1991]), whereas large discrepancies from GM have been observed in the upper ocean [Duda and Cox, 1989; Gregg and Kunze, 1991; Pinkel, $1984,1985]$.

To test the internal-wave breakdown hypothesis, measurements of microstructure and fine structure were incorporated into NATRE. A spatial survey was performed by R. Schmitt, J. Toole, and K. Polzin prior to injection, spring 1992. Intensive ship-tethered microstructure surveys were performed in the fall of 1992 and the spring of 1993 by $\mathrm{N}$. Oakey and collaborators, intended to directly measure turbulence and turbulent kinetic energy dissipation. A third data set, reported here, was collected during the intensive surveys using a Cartesian Diver autonomous profiler. Diver measurements of velocity profiles can be used to evaluate parameterizations of diffusivity in terms of shear through direct comparison with the $\mathrm{SF}_{6}$ experiment.

The Diver recorded velocity fine structure (most frequently attributed to internal gravity waves), density, and other parameters as it profiled. In November 1992, 53 velocity profiles were collected at site $A$ and 185 were collected at site B (Figure 1). In April 1993, 49 were collected at site $\mathrm{C}$ and 53 at site D (Figure 2). Profiles between 100 and $450 \mathrm{~m}$ depth were intended, but improper ballasting during $A$ and $B$ caused the Diver to fall faster than it rose, filling memory and cutting short the upward profiles, slightly reducing the data quantity.

Most of the 340 profiles provide continuous samples of shear (vertical difference of horizontal velocity), above the noise level, at vertical separations greater than $10 \mathrm{~m}$. The site $\mathrm{D}$ data are noise-free only at scales larger than $20 \mathrm{~m}$ because of an incorrect repair after deployment $\mathrm{C}$, but are still usable. The large quantity of shear sam- ples enable testing of the shear/dissipation/diffusivity parameterizations.

\section{Dissipation and Diffusivity Parameterization}

\subsection{Parameterization of Dissipation With Shear}

Gregg [1989] compared turbulent kinetic energy dissipation measurements ("dissipation", $\epsilon$ ) from the thermocline with concurrent fine-scale shear measurements. The relationship of these quantities was then compared with shear/dissipation dependencies derived from three internal-wave dissipation models, cited below. These formulas express dissipation as a function of internalwave energy density and buoyancy frequency $N$, under the assumption that velocity follows the GM wavenumber-frequency spectrum. Gregg uses properties of the GM spectrum to convert the energy dependence to shear dependence, which is sensible since shear is more intuitively associated with wave breaking than total wave energy. Gregg could not effectively test one additional model [Gargett and Holloway, 1984] using the data from variable-energy internal wave fields because it did not contain energy scaling. It has been pointed out that the conversion of energy dependence to shear dependence can lead to significant errors at energies greatly exceeding the GM level [Gargett, 1990]. This is not a problem in our study, since velocity and shear spectra are near GM.

In the Gregg study, a probablistic breaking model [Munk, 1981] yielded dissipation estimates at least 10 times the observed values. A nonlinear-interaction/energy-flux model [McComas and Müller, 1981] gave dissipation estimates roughly 3 times the observations. An expression derived from a random critical-layer/spectralflux model [Henyey et al., 1986] best fit the observations. After modification from energy-density to shear dependence, the formula is

$$
\begin{aligned}
\epsilon_{H W F}= & \left\{(1.67 / \pi) j_{*}^{2} b^{2} N^{2} E_{G M}^{2} f \cosh ^{-1}(N / f)\right\} \\
& \times\left[\overline{N^{2}} / N_{0}^{2}\right]\left[\overline{S_{10}^{4}} / S_{10 G M}^{4}\right] \quad\left[\mathrm{W} \mathrm{kg}^{-1}\right]
\end{aligned}
$$

where $N$ is the buoyancy frequency, $f$ is the Coriolis parameter, $N_{0}=0.0052 \mathrm{rad} \mathrm{s}^{-1}(3 \mathrm{cph}), S_{10 G M}$ is shear in the GM76 spectral model [Gregg, 1989] due to waves of wavelength greater than $10 \mathrm{~m}$, and $S_{10}$ is observed shear from the same wavelength band. The overbar indicates expected value or ensemble average. Other quantities are the the GM modal bandwidth parameter $j_{*}=3$, stratification scale factor $b=1300$, and the dimensionless energy $E_{G M}=6.3 \times 10^{-5}[$ Gregg, 1989]. The term in the large curly brackets equals $2.8 \times 10^{-10}$ at the average latitude of the observations, $26^{\circ} \mathrm{N}$. The inverse cosh term hovers near 5 for much of the main thermocline, and its importance can not be tested with these data. It is regarded as a constant by Gregg [1989] and Gregg and 


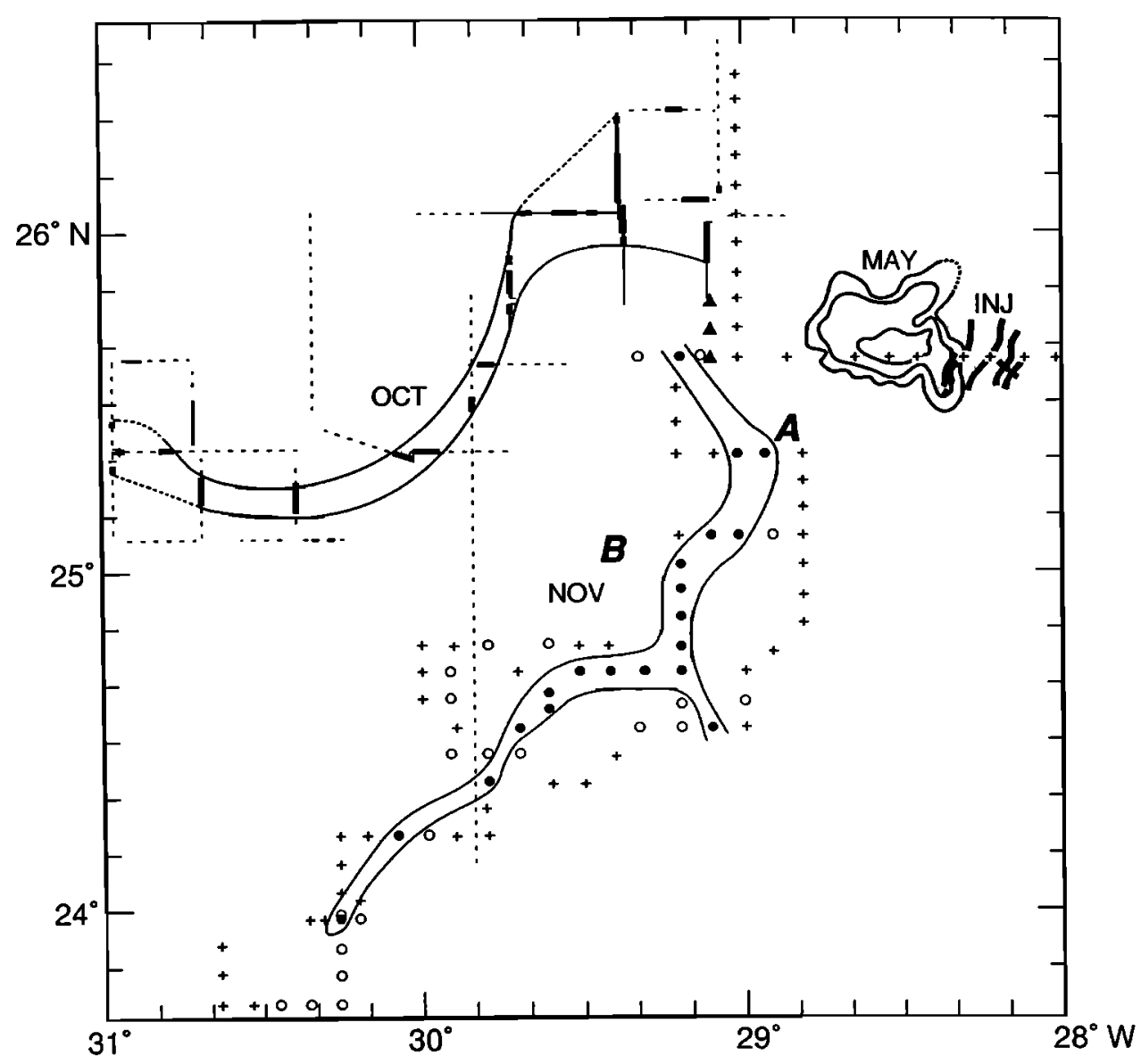

Figure 1. The locations of Cartesian Diver deployments A and B are indicated on this map derived from that of Ledwell et al. [1993]. Estimated locations of the $\mathrm{SF}_{6}$ streak during October and November 1992 sampling trips are shown. Solid circles and thick bars mark detection of high concentrations of tracer; pluses, open circles, and dashed lines mark lesser or background concentrations [see Ledwell et al., 1993]. The A launch location was $25^{\circ} 22.4^{\prime} \mathrm{N}, 29^{\circ} 2.3^{\prime} \mathrm{W}$; recovery location was $25^{\circ} 18.6^{\prime} \mathrm{N}, 29^{\circ} 18^{\prime} \mathrm{W}$. The B launch location was $24^{\circ} 58.8^{\prime} \mathrm{N}, 29^{\circ} 14.0^{\prime} \mathrm{W}$; recovery location was $24^{\circ} 55.7^{\prime} \mathrm{N}, 29^{\circ} 52.54^{\prime} \mathrm{W}$, some 35 miles $(56 \mathrm{~km})$ to the west, after 3 days of surface drifting. An initial ARGOS fix at recovery was between the launch and recovery sites, at $24^{\circ} 54.5^{\prime} \mathrm{N}, 29^{\circ} 22.0^{\prime} \mathrm{W}$.

Kunze [1991], and it is set to $\cosh ^{-1}\left(N_{0} / f_{26}\right)=5.1$ for thè remainder of this analysis, where $f_{26}$ is the Coriolis parameter for $26^{\circ} \mathrm{N}$.

A correction factor, revising $\epsilon_{H W F}$ upward, has been offered recently [Polzin et al., 1995]. This factor arises because Henyey, Wright, and Flatté used the GM81 spectral model [Munk, 1981] in their derivation, rather than the GM76 model which was used in Gregg's modification, and is $(7 / 5)^{2} \approx 2$. Harmoniously, Gregg [1989] found that $\epsilon$ hovered a factor of 2 higher than $\epsilon_{H W F}$ over a range of $N$ at latitude $34^{\circ} \mathrm{N}$, and offered an internal-wave dissipation parameterization for $34^{\circ} \mathrm{N}$ which was a factor of 2 higher than $\epsilon_{H W F}$ of (1). If the factor of 2 is included, the expression for $26^{\circ}$ latitude is

$$
\epsilon_{I W}=5.6 \times 10^{-10}\left[\overline{N^{2}} / N_{0}^{2}\right]\left[\overline{S_{10}^{4}} / S_{10 G M}^{4}\right]
$$

Another correction factor which is intended to improve the parameterization $\epsilon_{H W F}$ for non-GM wave fields has appeared [Polzin et al., 1995]. This is intended to account for variable energy dissipation caused by differing refraction rates of small-scale waves propagating in the shear of various larger-scale wave fields. Dissipation of small-scale wave energy is described in the model by refraction, with shifting of the small-scale waves to lower intrinsic frequency, subsequently reducing group velocity and increasing energy density. The energy-flux rate (dissipation rate) can be written as the expected value of $S^{2} k$, background shear squared times horizontal wavenumber, times the vertical wavenumber spectrum of velocity (energy spectrum) [Henyey et al., 1986]. This product scales with wavenumber inclination $k / m$ [Henyey, 1991] and thus wave frequency $\omega$; through the dispersion relation it is proportional to $\left[\left(\omega^{2}-f^{2}\right) /\left(N^{2}-\omega^{2}\right)\right]^{1 / 2}$. With the correction,

$$
\epsilon_{I W c}=\epsilon_{I W} \frac{\alpha}{\alpha_{0}} \frac{N}{f} \overline{\left(\frac{\omega^{2}-f^{2}}{N^{2}-\omega^{2}}\right)^{1 / 2}} \equiv \epsilon_{I W} X
$$




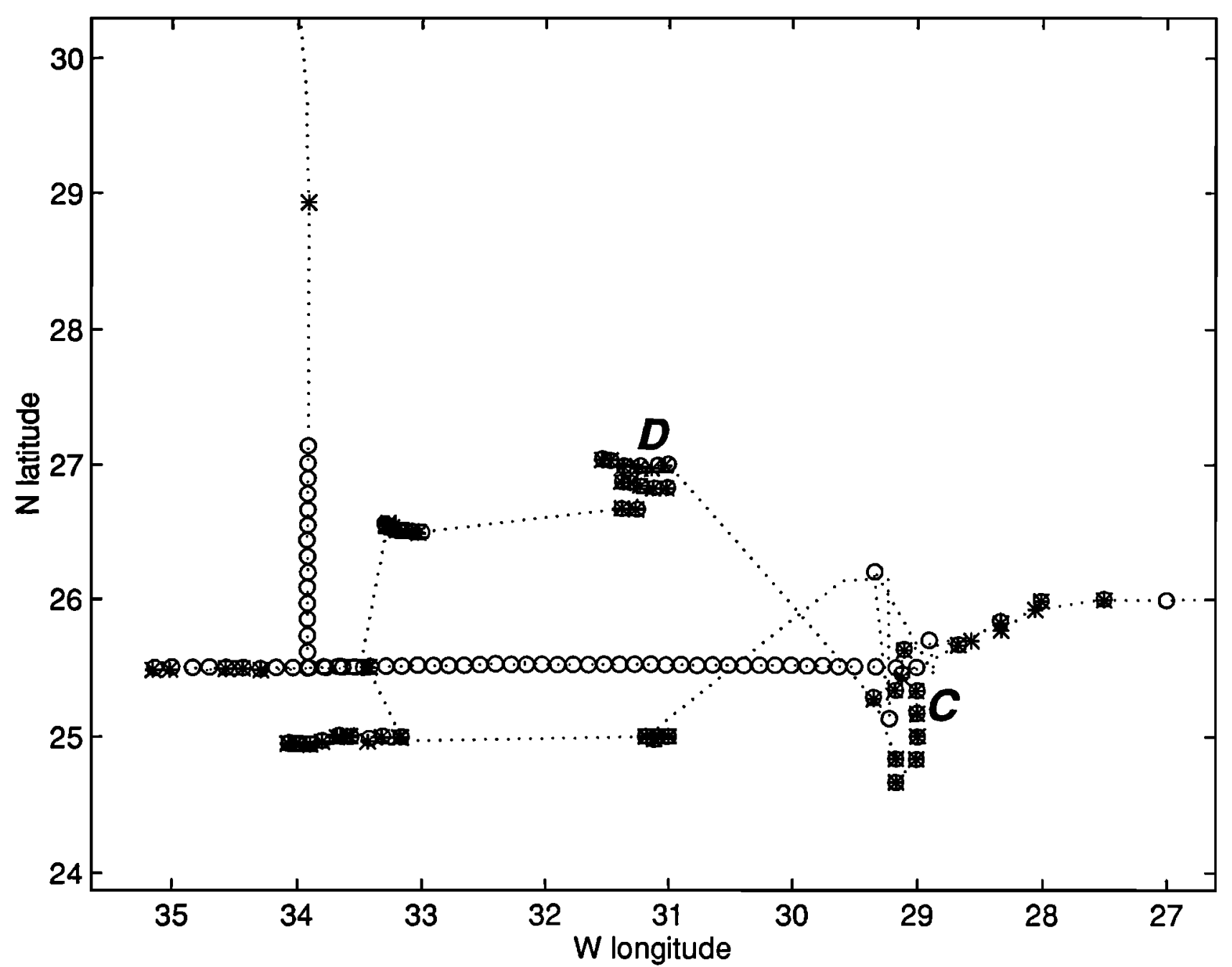

Figure 2. Deployments C and D are indicated on this ship track diagram for the 1993 Husdon trip. The asterisks mark Bedford Institute microstructure stations, and the open circles mark conductivity-temperature-depth (CTD) and tracer sampling stations. $\mathrm{SF}_{6}$ was found at nearly all the stations, in varying concentration (J. Ledwell, personal communication, 1993). The C launch was at $25^{\circ} 11.5^{\prime} \mathrm{N}, 29^{\circ} 3.8^{\prime} \mathrm{W}$, with first ARGOS fix at $25^{\circ} 14.2^{\prime} \mathrm{N}, 29^{\circ} 4.2^{\prime} \mathrm{W}$, and recovery 20 miles $(32 \mathrm{~km})$ westward. The D launch was at $26^{\circ} 59.4^{\prime} \mathrm{N}, 31^{\circ} 13.5^{\prime} \mathrm{W}$, with recovery at $26^{\circ} 57.6^{\prime} \mathrm{N}$, $31^{\circ} 11.0^{\prime} \mathrm{W}$.

where $\alpha$ is related to the shear-strain ratio by $\alpha=$ $\left(R_{\omega}+1\right) / R_{\omega}, R_{\omega}=\bar{S}^{2}\left(N^{2} \overline{\eta_{z}^{2}}\right)^{-1}$ is the observed shear to strain ratio, a function of internal wave frequencies in the data, and $\alpha_{0}=4 / 3$ is the $\alpha$ value in the GM model. An evaluation of the averaged background quantity in terms of $R_{\omega}$, which uses the hydrostatic approximation and is approximately true for $\omega$ near $f$, has been provided (K. Polzin, personal communication, 1994), resulting in

$$
X=\frac{3}{4} \frac{\left(R_{\omega}+1\right)}{R_{\omega}}\left(\frac{2}{R_{\omega}-1}\right)^{1 / 2}
$$

As a check, it can be seen that $X=1$ for a GM wave field with $R_{\omega}=3$.

\subsection{Parameterization of Diffusivity With Shear}

An expression derived from the turbulence kinetic energy (TKE) equation relates the eddy-diffusion coeffi- cient for density $K_{v}$ to the TKE dissipation, the density gradient $\left(N^{2}\right)$ and the flux Richardson number [Osborn, 1980]

$$
K_{v}=\frac{R_{f}}{\left(1-R_{f}\right)} \frac{\epsilon}{N^{2}} \quad\left[\mathrm{~m}^{2} \mathrm{~s}^{-1}\right]
$$

If one appeals to an upper limit (critical) flux Richardson number, typically $R_{f}<0.15$, representing a maximum possible loss of TKE to potential energy [Itsweire et al., 1993; Osborn, 1980], then an inequality arises,

$$
K_{v}<0.2 \frac{\epsilon}{N^{2}}
$$

with a rounded-off maximum mixing efficiency of $20 \%$. Using $\epsilon_{I W}$ for $26^{\circ}$ latitude,

$$
K_{v}<4 \times 10^{-6}\left[\overline{S_{10}^{4}} / S_{10 G M}^{4}\right]
$$


The parameterizations shown thus far contain estimates of the fourth moment of shear, which can be computed from velocity differences at the interval $\Delta z=10 \mathrm{~m}$. The model fourth moment is equal to twice the square of the model second moment [Gregg, 1989].

The second moment can also be used, determined by integrating spectra or by differencing velocities to obtain shear. In either case, if shear is an isotropic joint normal random variable, so that the fourth moment is twice the square of the second moment, the formula becomes

$$
K_{v}<4 \times 10^{-6}\left[\overline{S_{10}^{2}} / S_{10 G M}^{2}\right]^{2}
$$

A similar expression with an additional factor of 2 on the right-hand side was evaluated by Gregg and Kunze [1991], seemingly inadvertently. (The numbers in their Table 3 indicate that they use $\left[\overline{S_{10}^{4}} / S_{10 G M}^{4}\right]=$ $2 \times\left[\overline{S_{10}^{2}} / S_{10 G M}^{2}\right]^{2}$, whereas we use $\left[\overline{S_{10}^{4}} / S_{10 G M}^{4}\right]=$ $\left[\overline{S_{10}^{2}} / S_{10 G M}^{2}\right]^{2}$ ). The correction factor $X$ from the previous section can be applied to the previous two $K_{v}$ parameterizations, giving $K_{v c}$.

\section{Observations of Velocity and Shear}

\subsection{Cartesian Diver Instrument}

The Cartesian Diver is an autonomous profiling instrument which profiles ocean structure by alternately increasing and reducing its volume. The resultant alterations of buoyancy allow it to rise and fall over programmed depth intervals, if properly ballasted. The buoyancy changer mechanism is a piston in a cylinder, driven by a ball-bearing screw jack. The present configuration is described by Jacobs and Cox [1992].

The Diver has been outfitted to measure many variables while profiling. This study will concentrate on fine structure of horizontal velocities, that is, variations of velocities $u(z)$ and $v(z)$ over vertical scales of tens of meters. This measurement is accomplished by recording electric field variations. This is the geoinductive method of velocity measurement. The instrument profiles slowly, $\pm 0.15 \mathrm{~m} / \mathrm{s}$, and has sufficient horizontal drag so that it moves horizontally at the local horizontal water velocity [Duda et al., 1988]. Drag is provided by wings, which also spin the instrument as it profiles. About 32 profiles (16 round-trips) between 100 and 450 $m$ depth can be measured each day.

The Diver is equipped with $\mathrm{Ag}-\mathrm{AgCl}$ electrodes to measure the local electric field. They span $1.6 \mathrm{~m}$ to provide gain, with seawater exposure at the ends of the wings. With this electrode geometry, the electric field (voltage per unit length) in the moving reference frame of the Diver is

$$
\mathbf{E}(z)=\mathbf{E}_{s}+\mathbf{V}(z) \times \mathbf{F}
$$

where $\mathbf{V}=\hat{\mathbf{i}} U+\hat{\mathbf{j}} V+\hat{\mathbf{k}} W$ is the velocity of the instrument ( $U$ eastward, $V$ northward, $W$ upward), and
$\mathbf{F}$ is the geomagnetic induction. The constant voltage $\mathbf{E}_{s}$ in the solid Earth (geomagnetic) reference frame is not known. Under the conditions that the Diver moves in a Lagrangian fashion horizontally, so that $\hat{\mathbf{i}} U+\hat{\mathbf{j}} V=\hat{\mathbf{i}} u+\hat{\mathbf{j}} v$, the vertically varying portion of the field is given by

$$
\mathbf{E}^{\prime}(z)=\hat{\mathbf{i}}\left[F_{z} v(z)-F_{y} W\right]-\hat{\mathbf{j}} F_{z} u(z)
$$

so that voltage changes with depth are attributable to changes in horizontal water velocity and in the (positive upward) profiling rate $W$. Changes in $W$, measured directly with the pressure sensors, were observed to be small (less than those of Jacobs and Cox [1992]), so that setting the $W$ term constant does not influence shear estimates. $W$ is set to zero in the final analysis.

The electrodes have higher noise at lower frequencies, and would contribute noise comparable to $\mathbf{E}^{\prime}(z)$ if just dropped through the ocean. To circumvent this problem, the wings (horizontal drag elements) are set to cause the instrument to rotate once per $3 \mathrm{~m}$ depth, modulating the $\mathbf{E}^{\prime}$ signals of interest to a frequency band near $0.05 \mathrm{~Hz}$, where there is less noise.

The geoinductive signal levels are $0.36 \mu \mathrm{V}$ per $\mathrm{cm} / \mathrm{s}$ in the NATRE region $\left(F_{z} \approx 22300 \mathrm{nT}\right.$ during NATRE, calculated using the International Geomagnetic Reference Field (IGRF) model and associated software, National Geophysical Data Center, Boulder, Colorado). Velocity variations have reduced reliability (lower signal/noise ratio) as wavenumber increases, but generally are good to the wavenumber $0.1 \mathrm{cpm}$, occasionally better. The data from deployment $\mathrm{D}$ are good only to $0.05 \mathrm{cpm}$ because the Diver rotated too slowly and one voltage channel was too noisy to use (see section 3.2).

Temperature, conductivity, and pressure were also recorded during NATRE. Angular acceleration and highpass filtered pressure variations were recorded, to infer vertical water velocity [Jacobs and Cox, 1992]. All variables were sampled at $4 \mathrm{~Hz}$, or at $3.75 \mathrm{~cm}$ per sample, nominally, subject to proper ballasting. Conductivity gradient (essentially temperature gradient $[D u d a$ and Cox, 1988]) was also sampled at $64 \mathrm{~Hz}$. All measurements were made using voltage/frequency conversion and nearly continuous counters. Temperature and conductivity were recorded outboard on the wings, providing data along a helix of $1 \mathrm{~m}$ diameter and $3 \mathrm{~m}$ pitch.

\subsection{NATRE Diver Deployments}

Two sets of profiles, A and B, were obtained during the November 1992 microstructure sampling cruise of the R/V Oceanus. The locations are shown in Figure 1, which also shows the approximate location of the $\mathrm{SF}_{6}$ plume in October and November. Set A was taken from 2350 October 30 to 0407 November 1, 1992. Set B was taken from 2221 November 2 to 0623 November 7, 1992.

Two sets, C and D, were collected during the the most recent NATRE sampling cruise, spring 1993, aboard the CSS Hudson. Set C was taken from 1609 April 17 to 0349 April 19, 1993, although the Diver was not recovered until April 23 after drifting at the surface, tracked 
by ARGOS satellite. Set D was taken from 1543 April 24 to 0743 April 26, 1993. Figure 2 shows the locations of these deployments, along with spring $1993 \mathrm{SF}_{6}$ survey stations of the Hudson. $\mathrm{SF}_{6}$ was found at almost every station, so this is a minimum estimate of the patch extent. All four deployments were co-located (at least at their commencement) with concurrent intense microstructure surveys by Neil Oakey of the Bedford Institute of Oceanography.

The Diver was damiaged during the $\mathrm{C}$ recovery and was repaired. Two replacement salt-bridge wings, which have spiral pitch like propellers, spiraled oppositely from the original pair (and the remaining pair), but this was overlooked. The new configuration had reduced lift and increased drag, so that the instrument rotated once each $9 \mathrm{~m}$ rather than $3 \mathrm{~m}$. In addition, only one voltage channel was usable. The combination of effects reduced the wavenumber bandwidth of the $\mathrm{D}$ profiles. The reduced bandwidth can be seen in all profiles and spectra, and analysis of that data set is modified to include only wavelengths longer than $20 \mathrm{~m}$, in the manner of Gregg and Kunze [1991] who had similar noise limitations.

\subsection{Velocity Profiles}

Only up-going profiles are used here, one-half of the total data. Only these alternating profiles were used because the frequent profiles were partially coherent and somewhat redundant. Representative groups of profiles from the four data sets are shown in Figures 3-6. Vertical wavenumber spectra of each complex velocity profile $(u(z)+i v(z))$ were checked for proper red shape in the signal portion of the spectral domain, and expected sharp noise peak at the rotation wavelength. Eleven profiles yielded improperly shaped spectra and were not analyzed, 155 were analyzed, and four from the ends of profile sets were skipped. The bad profiles had either excessive electrode noise, connector noise, electronic noise, or counter errors, which could not be distinguished. The elimination of some of the profiles naturally broke the data sets into groups of profiles, listed in Table 1.

Each frame of Figures 3-6 shows profiles from two consecutive groups; not all profiles appear in the figures. The A, B and C profiles (Figures 3-5) have been low-pass filtered with zero-phase digital filters, designed independently for each profile, since each has a unique average profiling rate and sampling interval. The filters have unity gain below $0.1 \mathrm{cpm}$, a sharp cutoff, and strong attenuation $(-60 \mathrm{~dB})$ at $0.33 \mathrm{cpm}$, where the electrode noise appears.

The later A profiles (Figure 3b) show some noise spikes (high-wavenumber shear) which contribute negligibly to the shear variance. The same spikes are seen early in B (Figure 4a) but not later (Figure 4b). The $\mathrm{C}$ profiles (Figure 5) show much higher shear variance than $\mathrm{A}$ or $\mathrm{B}$.

The D profiles (Figure 6) appear smoother because their electrode noise was modulated to $0.1 \mathrm{cpm}$ (rather than 0.33 ), with a harmonic near $0.05 \mathrm{cpm}$ because of the single channel, and thus require a more stringent low-pass filter. The passband extends to $0.04 \mathrm{cpm}$, with complete rolloff at $0.08 \mathrm{cpm}$. The $-3 \mathrm{~dB}$ point of the filter is at $0.055 \mathrm{cpm}$, so that only signals at wavelengths greater than about $20 \mathrm{~m}$ remain.

\subsection{Vertical Wavenumber Spectra}

Vertical wavenumber autospectra of the up-going profiles are computed over the depth intervals shown in Figure 7 . The buoyancy changer operation at 450-m depth interfered with the electric field data, so the first 250 $s$ of data are not used (200 s for set D), roughly twice the length of the transient. Sections of profiles of 2048 $\mathrm{s}$ (A and B), $1150 \mathrm{~s}$ (C), and $1100 \mathrm{~s}$ (D) length were analyzed, beginning typically at $425 \mathrm{~m}$ depth, although

(a)
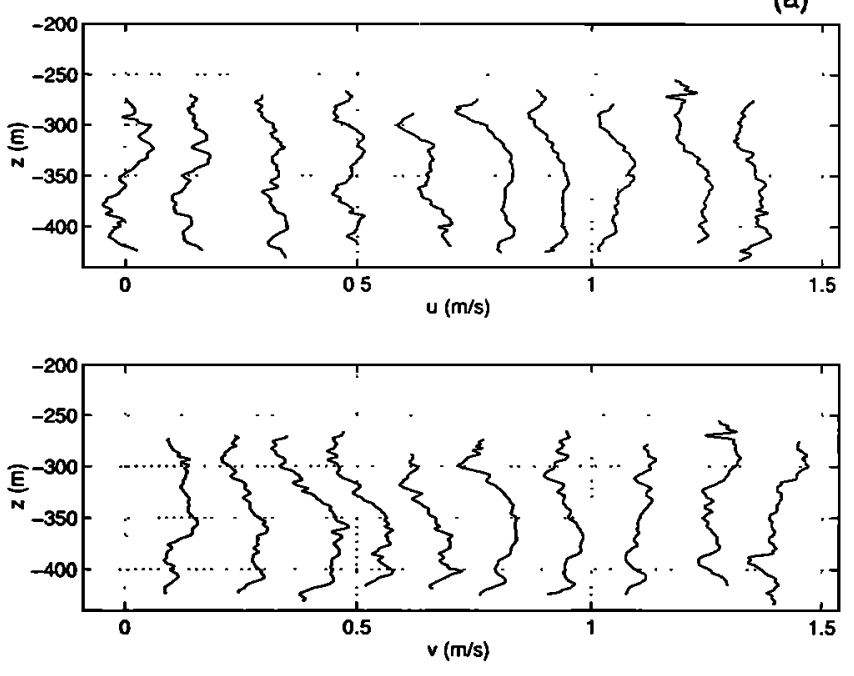

(b)
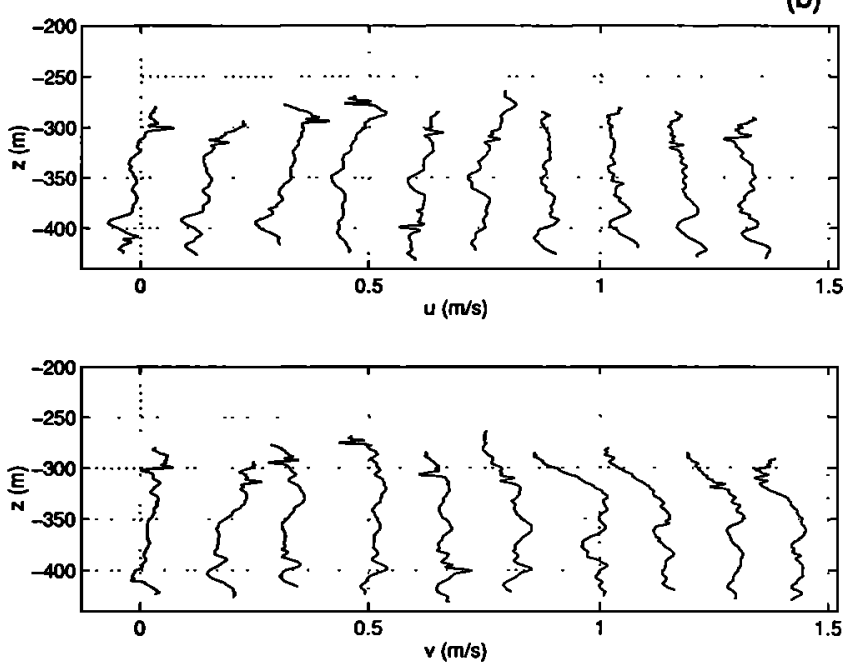

Figure 3. Eastward $(u)$ and northward $(v)$ velocity profiles from set A are shown for (a) profile groups 1 and 2 , and (b) groups 4 and 5. Some small noise features can be seen in the profiles. They do not significantly effect mixing estimates tabulated in section 4 . Pressure data are converted to depth for Figures 3 through 6 using the hydrostatic assumption and an average in situ density profile, giving small errors of no consequence. 
(a)
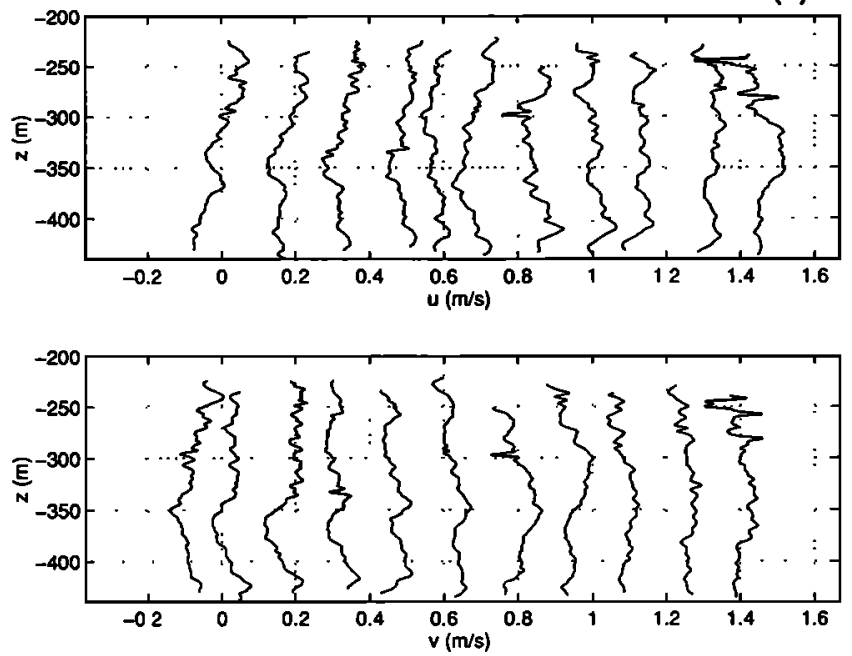

(b)
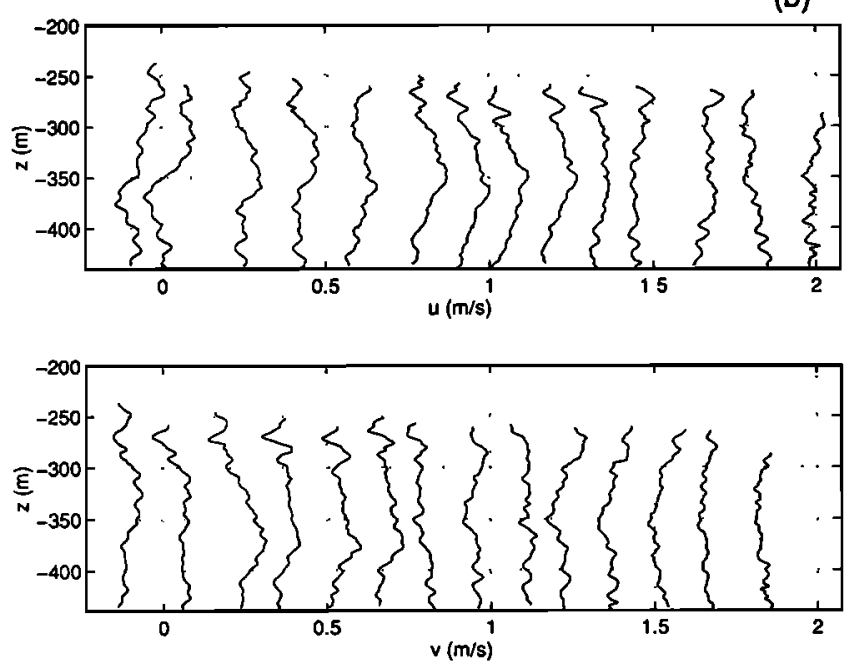

Figure 4. Similar to Figure 3, but set $\mathrm{B}$ velocity is shown for (a) groups 2 and 3 , including profile 16 , between the groups, which was not included in the final analysis, and (b) groups 6 and 7.

start depths were variable due to oceanic vertical velocities and control delays. Profiles of $N$ collected using the shipboard conductivity-temperature-depth (CTD) systems near the deployments show mean $N \approx 0.004$ $\mathrm{rads}^{-1}$ throughout those intervals, with fluctuations. The $\mathrm{B}$ deployment had a decreasing ascent rate after about 20 round trips, probably from leakage in the compressibility compensator, used to keep the instrument density anomaly (relative to seawater) constant during the profile.

The A, B, and C data are processed identically, as described here. The $\mathrm{D}$ data, with the rotation fault and the single voltage channel, were processed differently, as described later. A linear trend is removed from the unfiltered velocity profiles, removing unresolved lowwavenumber energy. Next, a Kaiser-Bessel taper with sidelobe level of about $-30 \mathrm{~dB}(\beta=3.8$ in MATLAB commercial software) is applied, reducing spectral sidelobe leakage. Complex autospectral estimates are calculated using the method of Duda and Cox [1989], yielding positive (pointing upward) and negative complex wavenumber spectral estimates, corresponding roughly to linear internal-wave energy propagation (group velocity) downward and upward, respectively [Leaman, 1976]. The spectra are not rigidly associated with downward or upward waves, since waves of frequency appreciably higher than $f$ will contribute equally to each spectrum. Since low-frequency energy is dominant, this spectral presentation is helpful. Spectra are ensemble averaged for the groups of profiles indicated in Table 1, giving the final spectral estimates, $S_{U U}$.

The D spectra are calculated in the same manner, with the exception of being filtered prior to detrending. This is necessary because the use of only a single volt-

(a)
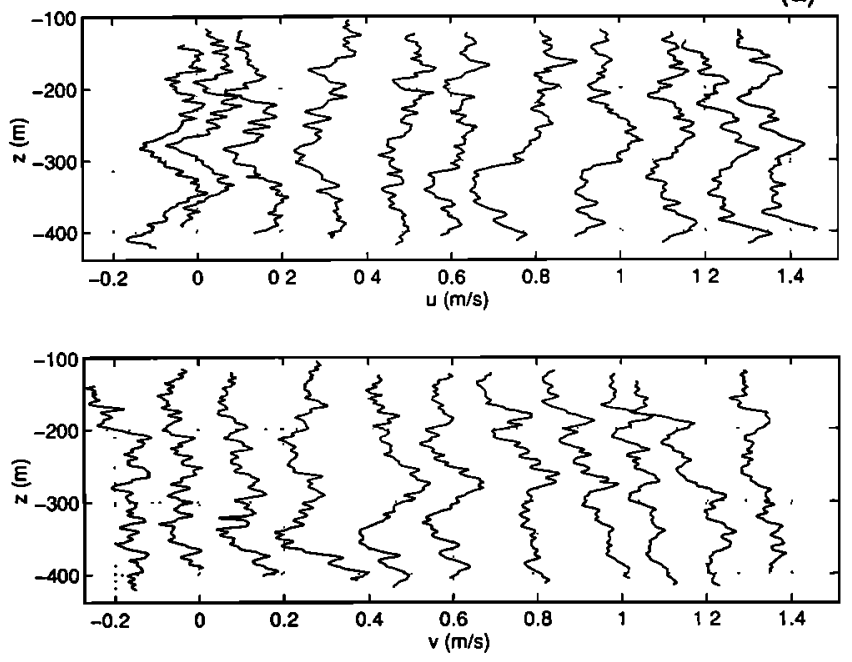

(b)
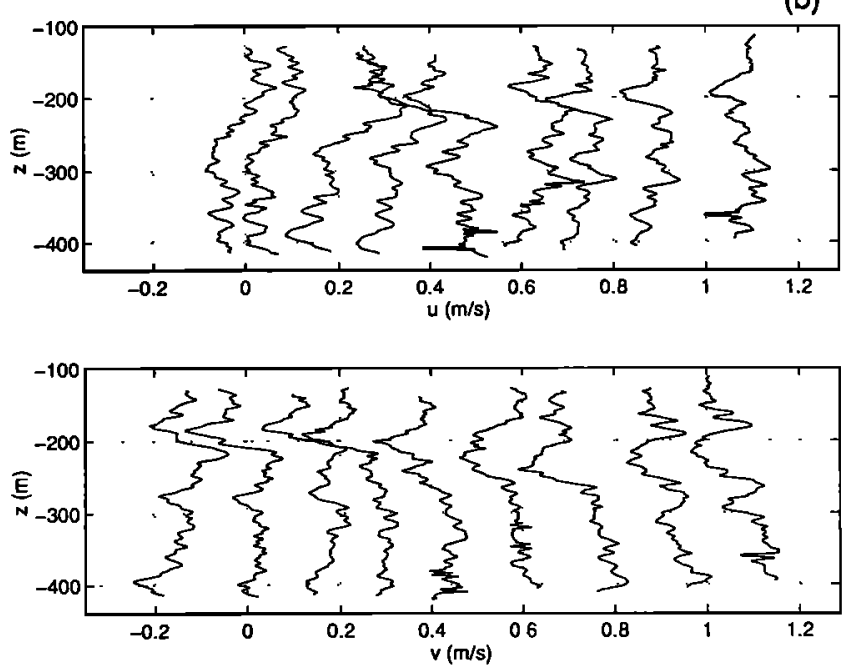

Figure 5. Similar to Figure 3 , but set $\mathrm{C}$ velocity is shown for (a) groups 1 and 2, and (b) groups 4 and 5 . The shear is higher than in sets A and B. 
(a)
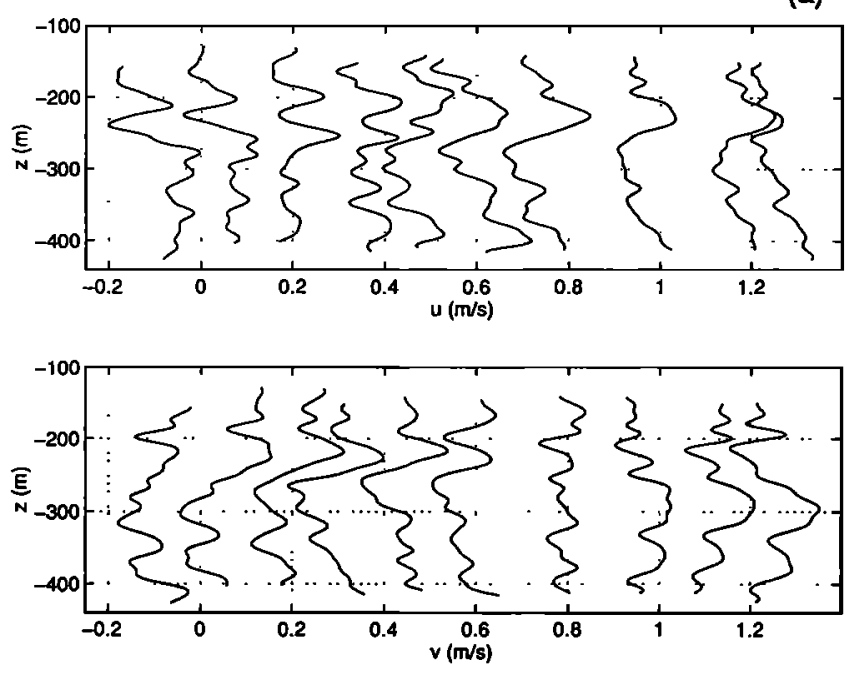

(b)
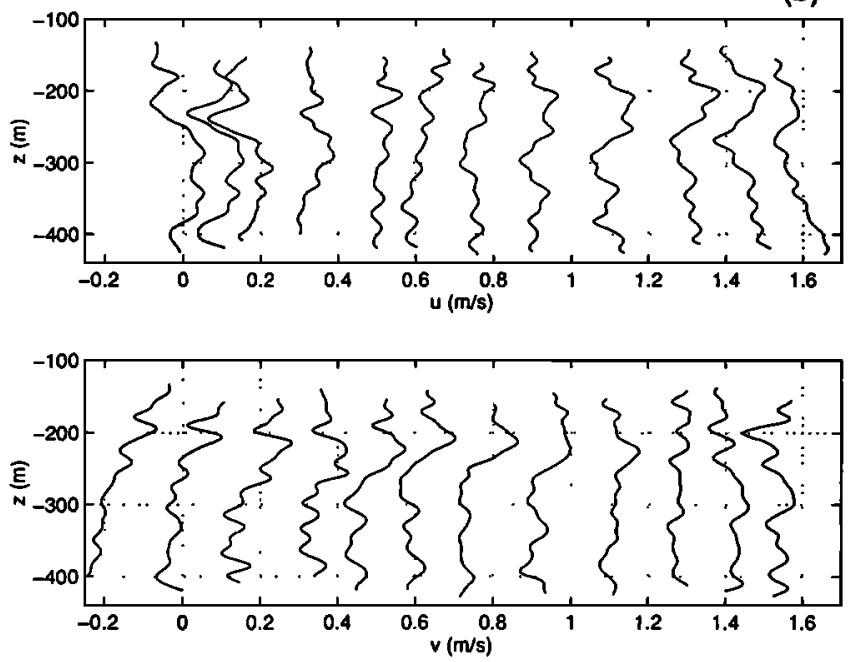

Figure 6. Similar to Figure 3, but set D velocity is shown for (a) groups 1 and 2, with higher shear, and (b) groups 4 and 5, with lower shear. Set $\mathrm{D}$ has been filtered with a more restrictive low-pass filter than the other sets.

age channel introduced noise at half the inadvertently small rotational wavenumber (noise at $0.055 \mathrm{cpm}$ in $\mathrm{D}$, as opposed to $0.33 \mathrm{cpm}$ in the others). The filter is described in the previous section.

Shear spectra are computed from the velocity spectra as described by Duda and Cox [1989],

$$
\psi(m)=m^{2}\left[S_{U U}(-m)+S_{U U}(m)\right] \quad m>0
$$

Figure 8 shows the shear spectra for sets A through D. The individual terms are also shown, $m^{2} S_{U U}(-m)$ and $m^{2} S_{U U}(m)$. Figure 9 shows the same spectra in variance-preserving format. Each of the figures also shows two reference spectra: the one-sided GM shear spectrum $\psi_{G M}$, and $2 \psi_{G M}$.

Sets A and B have spectra similar in shape to GM, slightly elevated above GM. Set $\mathrm{C}$ has an average level about triple GM, with further excess at wavenumbers $[0.04-0.1]$.

The D spectra show a high amount of upward propagating energy, residing in the energetic features near $250 \mathrm{~m}$ depth (Figure 6a), which are at the top of the section used for the spectrum (Figure 7). These spectra show the effects of the velocity filtering, the rolloff at $0.04 \mathrm{cpm}$. Set D hovers at 4 times the GM shear spectral level at wavelengths from 0.02 to $0.05 \mathrm{cpm}$.

The spectra are close enough to the GM form from $100-\mathrm{m}$ to $10-\mathrm{m}$ wavelength to allow evaluation of the $\epsilon_{H W F}$-derived expressions. If the shear spectra began dipping at wavenumbers less than $0.1 \mathrm{cpm}$, the relation of internal-wave energy density $E$ to $S_{10}^{2}$, upon which all of the quoted scalings depend, would be questionable [Gargett, 1990]. This point has been discussed by Polzin et al. [1995].

\subsection{Statistics of $10-m$ Interval Shear}

To verify that shear is a random variable associated with a field of internal waves of high dimensionality, thus satisfying the assumptions of the HWF dissipation model, we can investigate the probability distribution functions of shear. We use the filtered velocity profiles to compute shear at $10 \mathrm{~m}$ interval, using the expression of Gregg [1989],

$$
S_{10}^{2}=2.11\left[\left(\frac{\Delta u}{\Delta z}\right)^{2}+\left(\frac{\Delta v}{\Delta z}\right)^{2}\right]=2.11\left[S_{x}^{2}+S_{y}^{2}\right]
$$

where $\Delta z=10 \mathrm{~m}$. The factor 2.11 corrects the first differencing to allow direct comparison with variance from spectral integrals to $0.1 \mathrm{cpm}$. The velocity profiles are not detrended, as they are for spectral analysis (section 3.4). Set $\mathrm{D}$ has $\Delta z=20 \mathrm{~m}$ because of the instrument problems.

Figure 10 shows histograms of shear components, $S_{x}$ and $S_{y}$, for selected groups from the four data sets. The kurtoses (fourth moments normalized by the variance squared) are listed in the figure. For all of the records they are near 3 , the value for normal random variables. The histograms are similar in shape to the example normal distributions. The examples have the average standard deviation of the two component shears. We have not performed a detailed examination of shear statistics [Gregg et al., 1993], but we believe that discrepancies between the GM spectral model and the reality of the NATRE wave field, between assumptions in the HWF dissipation model and reality, and between turbulent mixing hypotheses and reality, taken in the aggregate, will overshadow a moderate departure of our statistics from normality.

The mean square error of each shear-component variance estimate can be derived if the components are Gaussian random variables with zero mean. In that case, the mean square error of each estimated meansquare value (equal to the variance if the mean is zero) is $\operatorname{MSE}_{n}=J^{-1}\left[\left\langle S_{n}^{4}\right\rangle-\left\langle S_{n}^{2}\right\rangle^{2}\right]$, or $2 J^{-1}\left\langle S_{n}^{2}\right\rangle^{2}$, where $n=x$ or $y, S_{n}$ is the true value of rms shear, and $J$ is the num- 
Table 1. Summary of Statistical Properties of Profile Groups

\begin{tabular}{|c|c|c|c|c|c|c|c|}
\hline Set & Group & Quantity & Up-Going Profiles Used & $\overline{S_{10}^{2}} ; * 10^{-5} \mathrm{~s}^{-2}$ & $\left\langle\eta_{z}^{2}\right\rangle$ & $R_{\omega}$ & $X$ \\
\hline \multirow[t]{5}{*}{ A } & 1 & 5 & $3-7$ & 2.0 & 0.100 & 12.3 & 0.34 \\
\hline & 2 & 5 & $8-12$ & 1.4 & 0.108 & 8.3 & 0.44 \\
\hline & 3 & 5 & $13-17$ & 1.5 & 0.094 & 10.2 & 0.38 \\
\hline & 4 & 5 & $18-22$ & 1.5 & 0.096 & 9.9 & 0.39 \\
\hline & 5 & 5 & $23-27$ & 1.5 & 0.128 & 7.5 & 0.47 \\
\hline \multirow[t]{13}{*}{$\mathbf{B}$} & 1 & 7 & $1-7$ & 1.8 & 0.095 & 12.0 & 0.35 \\
\hline & 2 & 6 & $10-15$ & 2.0 & 0.182 & 6.9 & 0.50 \\
\hline & 3 & 4 & $17-20$ & 2.2 & - & - & - \\
\hline & 4 & 7 & $23-29$ & 1.7 & - & - & - \\
\hline & 5 & 7 & $30-36$ & 2.0 & - & - & - \\
\hline & 6 & 7 & $37-43$ & 1.6 & - & - & - \\
\hline & 7 & 7 & $44-50$ & 1.5 & - & - & - \\
\hline & 8 & 7 & $51-57$ & 1.7 & - & - & - \\
\hline & 9 & 7 & $59-65$ & 2.3 & - & - & - \\
\hline & 10 & 7 & $66-72$ & 2.5 & - & - & - \\
\hline & 11 & 7 & $73-79$ & 2.4 & - & - & - \\
\hline & 12 & 7 & $80-86$ & 2.2 & - & - & - \\
\hline & 13 & 2 & $87-88$ & 2.9 & - & - & - \\
\hline \multirow[t]{5}{*}{$\mathrm{C}$} & 1 & 5 & $1-5$ & 6.0 & 0.199 & 18.8 & 0.26 \\
\hline & 2 & 6 & $6-11$ & 3.3 & 0.214 & 9.8 & 0.39 \\
\hline & 3 & 2 & $13-14$ & 3.5 & 0.091 & 24 & 0.23 \\
\hline & 4 & 5 & $16-20$ & 3.5 & 0.113 & 19 & 0.26 \\
\hline & 5 & 4 & $21-24$ & 4.5 & 0.142 & 20 & 0.26 \\
\hline \multirow[t]{5}{*}{ D } & 1 & 4 & $1-4$ & 2.4 & 0.087 & 17.4 & 0.28 \\
\hline & 2 & 5 & $6-10$ & 1.7 & 0.110 & 9.4 & 0.40 \\
\hline & 3 & 5 & $11-15$ & 1.7 & 0.123 & 8.6 & 0.43 \\
\hline & 4 & 6 & $16-21$ & 1.1 & 0.074 & 9.5 & 0.40 \\
\hline & 5 & 6 & $22-27$ & 1.1 & 0.079 & 8.6 & 0.43 \\
\hline
\end{tabular}

*For D, $\overline{S_{20}^{2}}$ is used instead of $\overline{S_{10}^{2}}$. Values are computed using technique 1. For comparison with $\mathrm{A}, \mathrm{B}$, and $\mathrm{C}$, $\overline{S_{\mathrm{l} O G M}^{2}}$ is slightly less than 1.2 at the observed $N$; for comparison with $\mathrm{D}, \overline{S_{20 G M}^{2}}=0.54$.

ber of independent observations. The rms error is then equal to $\left(2 J^{-1}\right)^{1 / 2}$ times the shear variance. The problem reduces to the determination of $J$. For six profiles of length $180 \mathrm{~m}$, typical of our profile groups, there may be 108 independent $10-\mathrm{m}$ shear estimates, such as with the data of Gregg et al. [1993]. Since the total variance is equal to the $x$ plus $y$ variances, we can double $J$. If all the profiles are independent, then the rms error is $10 \%$ of the variance. If one in three is independent, then the fractional error increases from 10 to $17 \%$. If one in five is independent, corresponding to a 7.5 hour decorrelation period, as suggested by strain measurements [Pinkel and Anderson, 1992], then the error increases to $22 \%$. These are estimated standard errors for shear variance. Using chi-square statistics and 43 degrees of freedom ( $216 / 5$, using the 7.5 hour decorrelation time), $95 \%$ confidence intervals for the variance estimates are 0.62 to 1.46 . This also applies to spectrally derived variance.

\subsection{Strain Observations}

The stain variance is required to compute the shear - strain ratio $R_{\omega}$ and the correction factor $X$. The re- peated profiling of the Diver allows direct estimation of vertical displacement $\eta$ and strain $\eta_{z}$. Displacements are computed at a discrete set of temperatures, $T_{\imath}$, using observed departures from an estimated mean profile. The profiles are filtered with 180-point (5-m) triangle filters, which reduces noise, eliminates overturns, and makes the profiles monotonic. The mean profile is calculated by finding the mean depths of the $T_{i}$ for each data set, $\bar{z}\left(T_{i}\right)$. Subtraction gives $\eta\left(T_{i}\right)=z\left(T_{i}\right)-\bar{z}\left(T_{i}\right)$. The resulting $\eta$ are mapped to depth by using the inverse function of $\bar{z}\left(T_{i}\right)$, and then interpolated and resampled at $1-\mathrm{m}$ depth intervals, giving $\eta(z)$. Figure 11 shows the five temperature profiles $z\left(T_{i}\right)$ from set $\mathrm{C} 1$, with the mean computed over the duration of $C$. The five corresponding $\eta(z)$ are also shown.

The strain variance is computed spectrally, in the same manner as the spectral $10-\mathrm{m}$ shear computation, using the same grouping. The integration is stopped at $20 \mathrm{~m}$ for $\mathrm{D}$, as with shear. The profiles $\eta(z)$ are detrended, and the Kaiser-Bessel taper is applied. The resulting displacement spectra are multiplied by the wavenumber squared, giving strain spectra, which are integrated to yield $\left\langle\eta_{z}^{2}\right\rangle$. Table 1 contains $\left\langle\eta_{z}^{2}\right\rangle, R_{\omega}$, and 

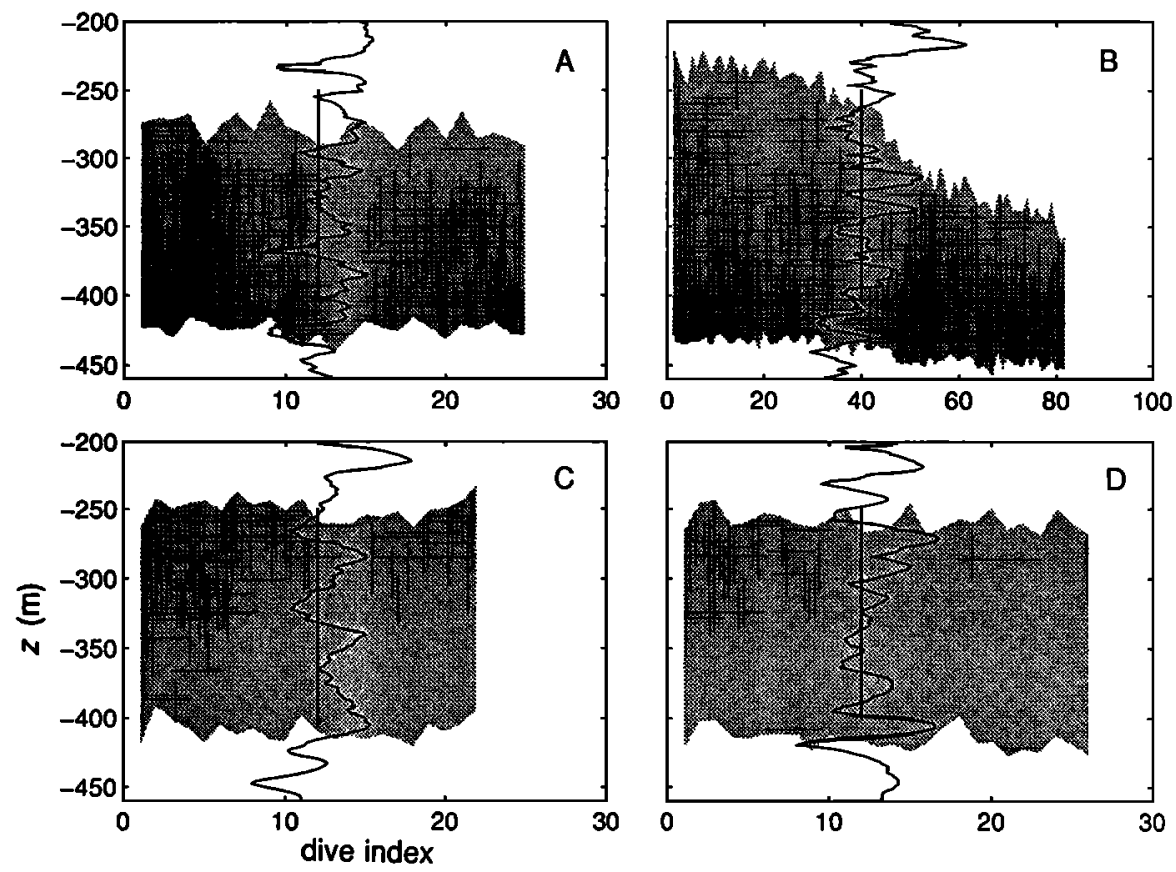

Figure 7. The depth sections of the profiles analyzed in the four sets are indicated by the shading. The vertical axis is depth, the horizontal axis is profile number. Profiles of buoyancy frequency are superimposed, taken from shipboard CTD casts at the time of launch. $N=0$ is at the left-hand edge (coincident with profile number 0 ), and $N=0.004 \mathrm{rads}^{-1}$ is shown with a line. It appears that $N$ constant at 0.004 is a good approximation at the sampled depths.
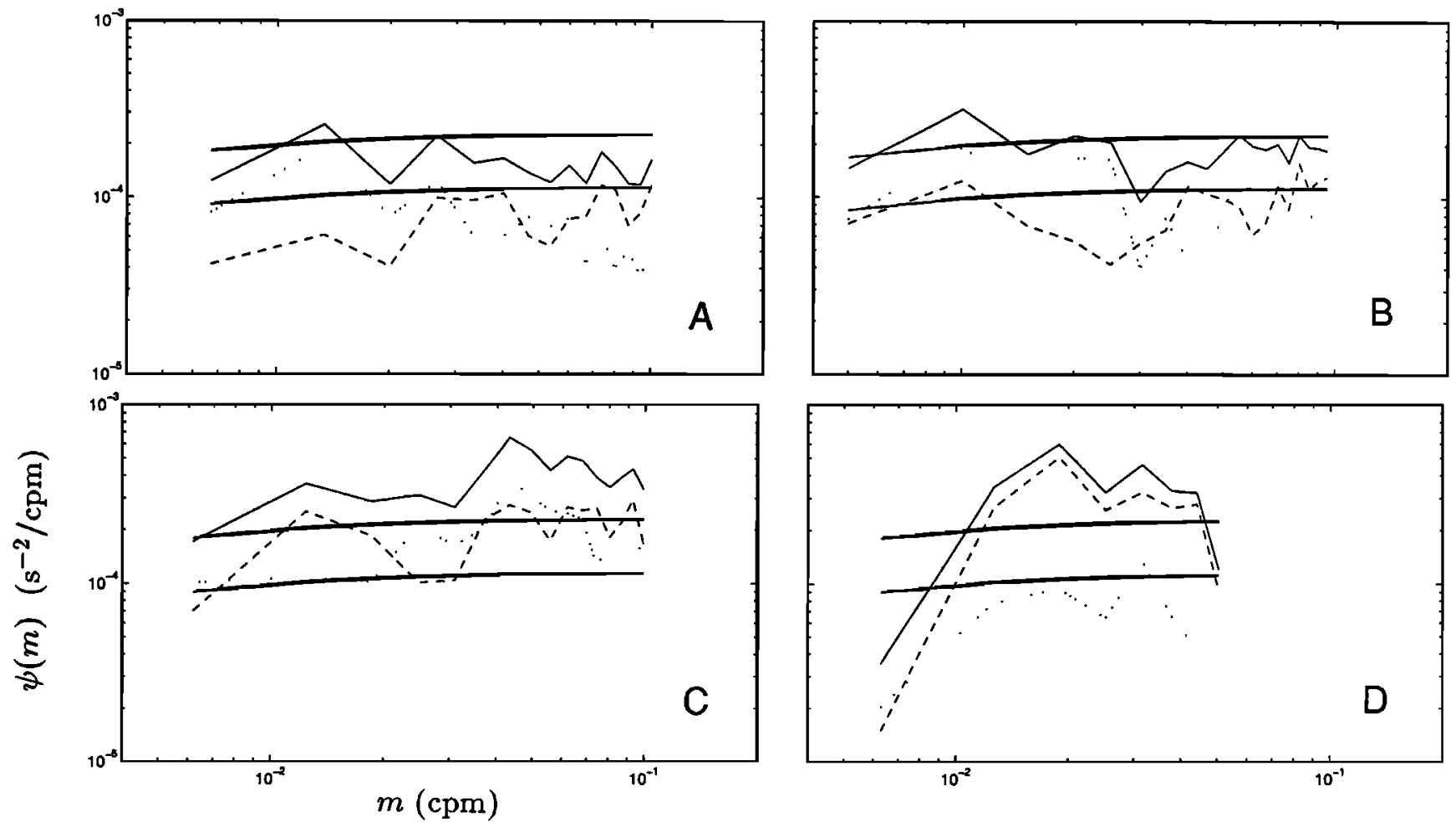

Figure 8. Shear spectra from the four data sets are shown. The solid lines are the one-sided (total) spectra, the dashed are the upward wavenumber spectra, and the dotted are the downward wavenumber spectra. The smooth reference lines are taken from the GM model spectrum. The lower ones are the GM model total spectra, and the upper ones are twice the GM total spectra. The A, C and D spectra utilize about 25 profiles, or 100 degrees of freedom at the higher wavenumbers where the successive profiles are uncorrelated, giving approximate $95 \%$ confidence intervals between 0.77 and 1.35 times the estimated value for the total spectra, 0.70 and 1.54 times the estimate for the directional spectra. The B spectra use 82 profiles, for smaller intervals of 0.86 to 1.17 for the total spectra, 0.81 to 1.26 for the directional spectra. 

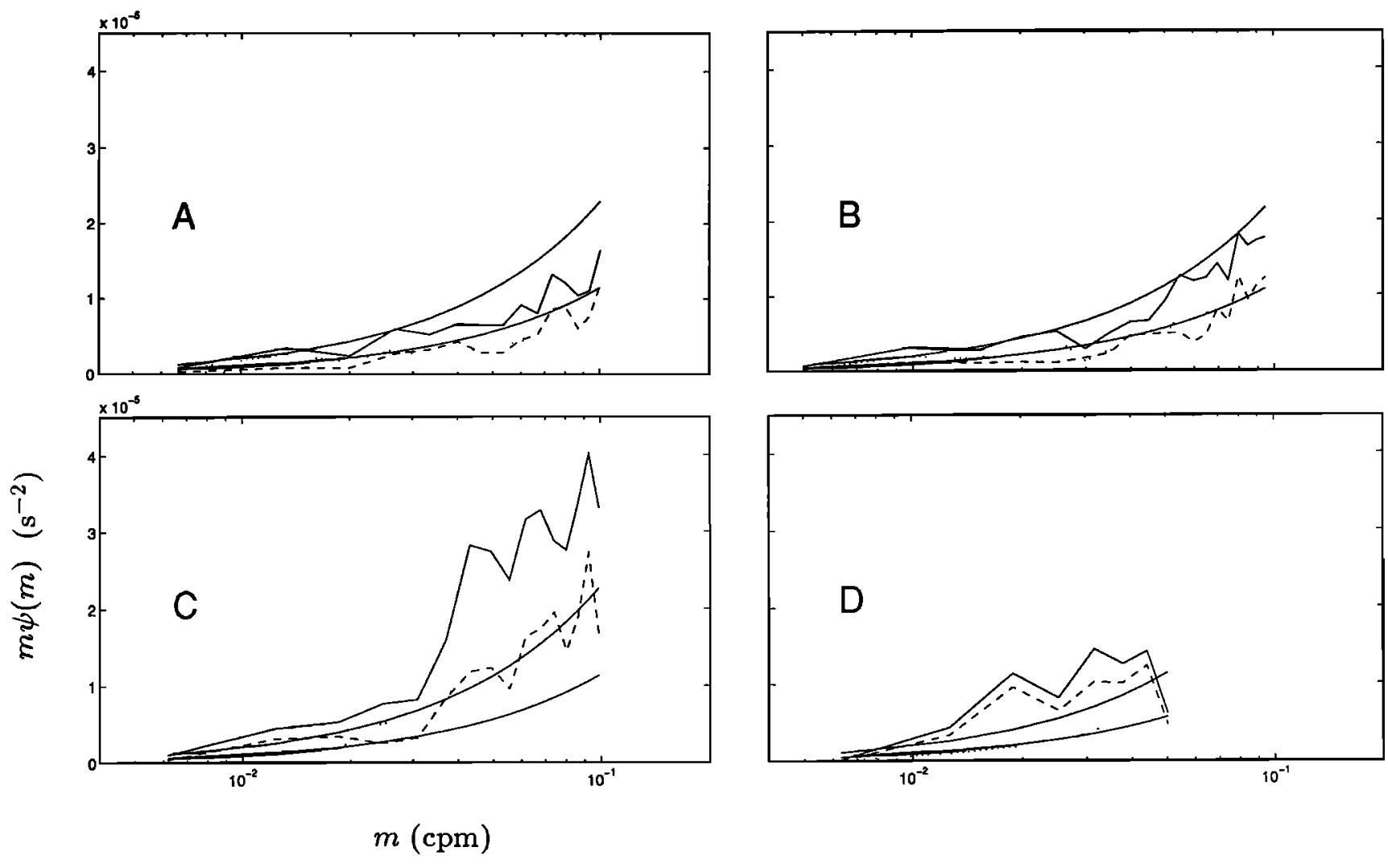

Figure 9. These are the spectra of Figure 8 plotted in variance-preserving format. The ordinate is the wavenumber times the spectral estimate, on a linear scale; the abscissa is logarithmic wavenumber. The various lines have the same meaning as in Figure 8 . Most of the shear exceeding GM in set $C$ is clearly seen to reside at wavelengths shorter than $25 \mathrm{~m}$.

$X$ values. The temperature measurement failed after group 2 of $\mathrm{B}$. The ratio $R_{\omega}$ always exceeds the GM value of 3 . It is generally near 10 , except it is near 20 for set $C$, which also has the highest shear. Set $C$ thus has the smallest $X$ corrections. These $R_{\omega}$ are all higher than the value of 4.8 quoted by Polzin et al. [1995] for this region in spring 1992 .

\section{Estimated Dissipation and Diffusion}

The HWF-based diffusivity parameterizations of Gregg [1989] and Gregg and Kunze [1991] can be evaluated in a variety of ways. We use three techniques to calculate shear from the velocity profiles. They give comparable results. They use either spectra (calculated as in section 3.4) or difference shear (calculated as in section 3.5). The depth intervals stated in section 3.4 are used throughout. The upper-bound parameterizations (7) and (8) are evaluated presuming equality.

The techniques are (1) spectral estimation of the second moment of shear at $10 \mathrm{~m}$, using integrals of spectra of unfiltered velocity profiles and parameterization (8); (2) 10-m difference estimation of shear second moment, using filtered velocity and expression (8); and (3) 10-m difference estimation of shear fourth moment, using filtered velocity and expression (7). Nonnormal aspects of the shear will cause differences between techniques 2 and 3 , while effects of the filter, detrending, and taper will give differences between techniques 1 and 2 . Set D is treated slightly differently: $20-\mathrm{m}$ comparisons are substituted for 10-m comparisons given in the expressions, similar to the treatment of Gregg and Kunze [1991].

Technique 1 has been used previously for $25-\mathrm{m}$ shear [Gregg and Kunze, 1991], and technique 3 has also been used [Gregg, 1989]. For techniques 2 and 3 we use interleaved $10-\mathrm{m}$ shear computed three to four times per meter, so not all shear samples are independent. We believe this reduces the effects of noise without causing attenuation from vertical averaging. By interleaving, we mean that $10-\mathrm{m}$ shear is computed at vertical intervals less than $10 \mathrm{~m}$.

Evaluations are done separately for each profile group within each data set, since stationarity over the sets is not assured. The profile groups are listed in Table 1. Each group is further divided into deep and shallow halves, which are evaluated separately to determine depth variation. This gives three depth ranges for each profile group: the deep, the shallow, and the union of the two. The confidence intervals can be deduced from the shear variance error discussion of section 3.5. Using the 43-degree-of-freedom estimates, the $95 \%$ confidence intervals for parameterized $K_{v}$ (the shear vari- 

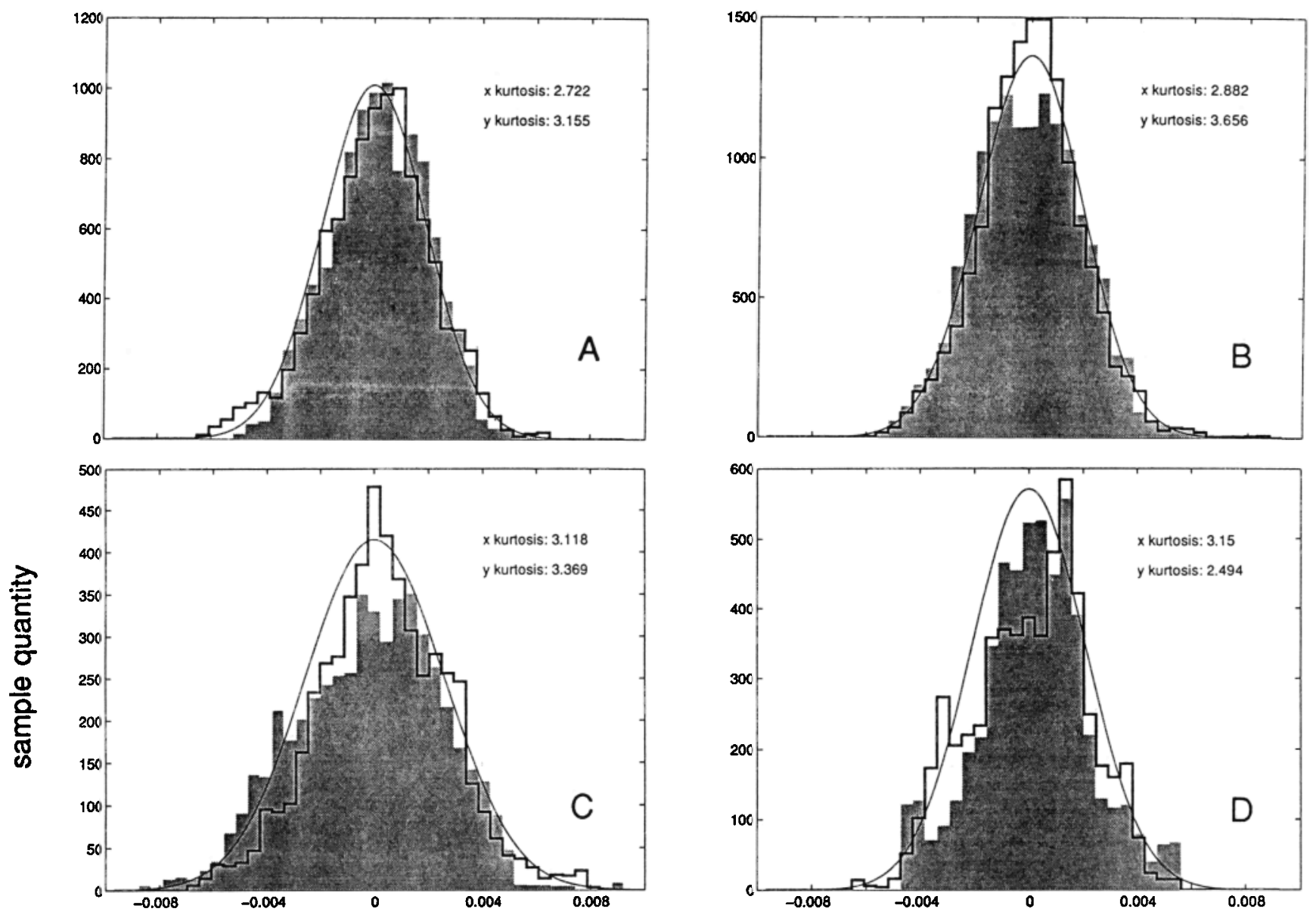

$$
S_{x}, S_{y}\left(\mathrm{~s}^{-1}\right)
$$

Figure 10. Histograms of $10-\mathrm{m}$ shear for selected portions of the four data sets (20-m shear for set $D$ ) show that the sampled shear is approximately a normal random variable. The shaded areas show the $u$ shear, and the stairsteps show the $v$ shear. The kurtoses of the shear components are also indicated. The smooth lines show normal distributions with half the means and the same variances as the sums of the shear distributions. The shear is calculated for velocities shown in Figures 3 through 6: (a) shear from set $\mathbf{A}$ groups 1 and 2 (Figure 3a), (b) shear from set B groups 6 and 7 (Figure 4b), (c) shear from set C groups 4 and 5 (Figure 5b), and (d) shear from set D groups 1 and 2 (Figure 6a).

ance squared) are 0.39 to 2.13 . Since the number of profiles per group varies, these confidence intervals also vary.

Figures 12-15 show the results for $K_{v}$ using $\epsilon_{I W}$, without the correction factor $X$. The set $\mathrm{A}$ shear is close to GM (Figures $8 \mathrm{a}$ and $9 \mathrm{a}$ ), giving $K_{v}=4 \times 10^{-6}$, less than half the summer $\mathrm{SF}_{6}$ result, so the parameterization underestimates the data (Figure 12). The results are comparable for the shallow and deep portions of the record, and the three techniques give similar results.

The set B shear shows results (Figure 13) comparable to set $A$, except one group shows higher shear and thus higher estimated $K_{v}$ in the shallow region. The B and C sets show the greatest discrepancies between the methods. The extreme B estimates from the fourth-moment method exceed those from the second moment method, so the statistics may not be compatible with normality. The spectral method subdues the extreme values, perhaps because of the taper function. The shallow portion of the record shows slightly more mixing than the deep portion during the first half of the record. Note also that the depths of the shallow and deep sampling volumes change throughout the record because of the shorter profiles. At the later stage, the shallow volume actually includes depths found in the deep volume at the beginning of the record.

The set $\mathrm{C}$ evaluation shows $K_{v}$ estimates which consistently exceed the long-term $\mathrm{SF}_{6}$ observations (Figure 14). The spectral method gives a much larger estimate for the first group and slightly higher estimates for the other groups, perhaps because of noise leakage into the measurement spectral band from the unfiltered velocities.

The set $\mathrm{D}$ results show agreement between the three methods (Figure 15), and a diminishing trend over the 1.5-day interval, dropping to a level below the long-term 

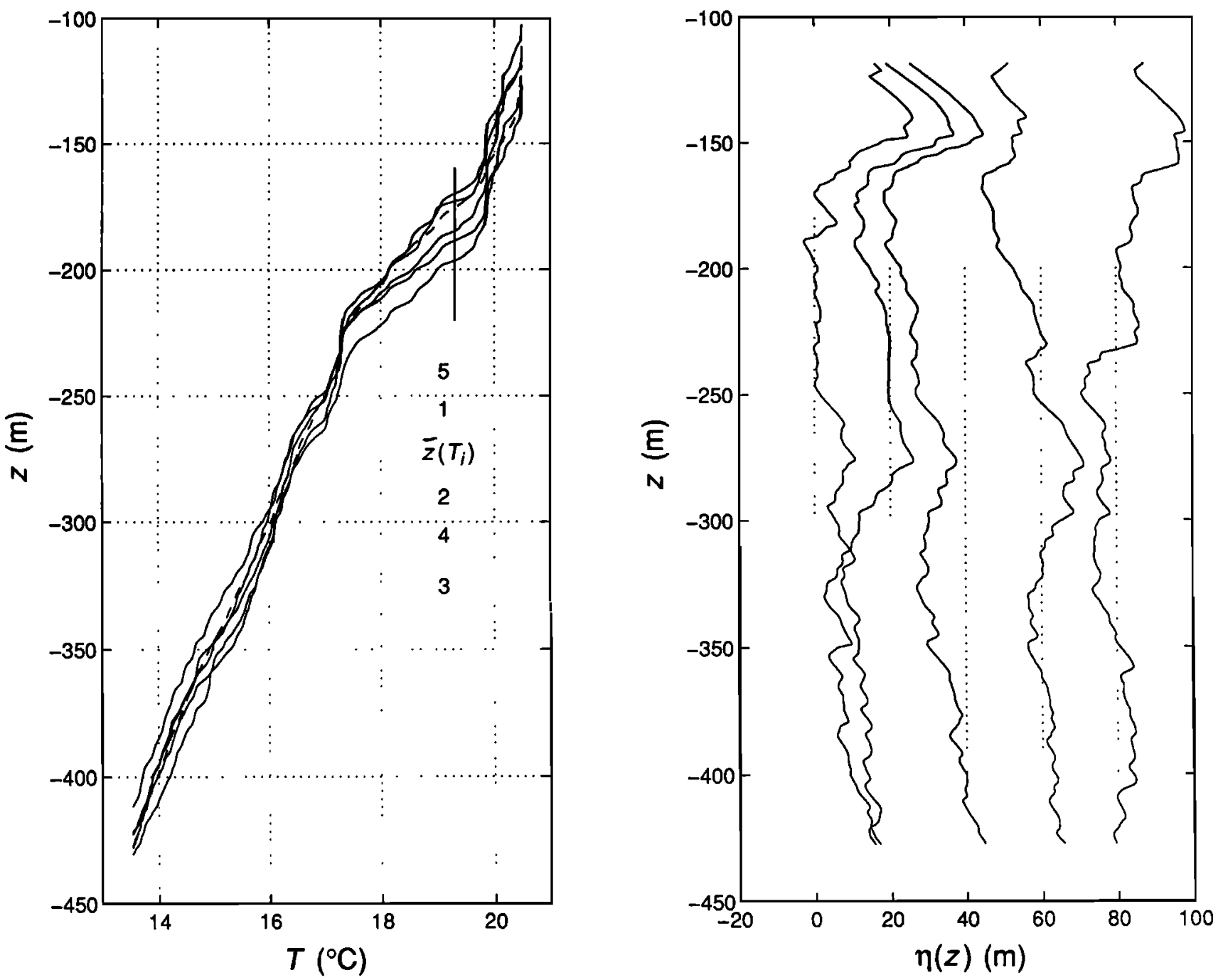

Figure 11. (left) The five temperature profiles $z\left(T_{i}\right)$ from group C-1 are shown (solid lines), with the mean profile $\bar{z}\left(T_{i}\right)$ (dashed line) computed from groups C- 1 through $\mathrm{C}-5$. The numbers indicate the profile numbers, from top to bottom, along the index line at 19.3 degrees. (right) The displacements derived from the $z\left(T_{i}\right)$ profiles are shown, 1 through 5 from left to right, each offset $20 \mathrm{~m}$ in displacement from the last. The dotted lines indicate $\eta=0$ for each of the profiles.

$\mathrm{SF}_{6} K_{v}$. The shallow results slightly exceed the deep results. The differences in shear over the four data sets illustrate the variability of shear and the difficulty of relating intensive, detailed internal wave measurements to long-term mixing.

Table 2 shows the arithmetic means of the uncorrected $(X=1)$ group diffusivities of the four data sets, plus overall means. On the whole, the parameterized values exceed the $\mathrm{SF}_{6}$ diffusivities. The fall values $(\mathrm{A}, \mathrm{B})$ average about $1.0 \times 10^{-5}$. The spring values $(C, D)$ average $4.5 \times 10^{-5}$ for technique 1 and about $2.6 \times 10^{-5}$ for techniques 2 and 3 .

Table 3 shows the means of the diffusivities with the factor $X$. These values are substantially lower than the $\mathrm{SF}_{6}$-derived diffusivity, and are consistent with saltfingering doing some of the diapycnal mixing. The fall values average about $0.4 \times 10^{-5}$. The spring values average $1.5 \times 10^{-5}$ for technique 1 and $0.8 \times 10^{-5}$ for techniques 2 and 3 .
The $\mathrm{SF}_{6}$ experiment showed elevated mixing in the winter compared to the summer. The elevated shear (and thus elevated $K_{v}$ estimates given in Tables 2 and 3) which was observed in the springtime (C,D) relative to autumn $(A, B)$ would be consistent with this, under the condition that the observed autumn/spring shear ratio was somewhat representative of the integrated summer/winter ratio. Table 4 shows group $K_{v}$ estimates, both with and without the factor $X$.

\section{Summary}

Vertical wavenumber spectral shapes and energies have been computed for four sets of velocity profiles taken in the NATRE region. A major result is that the shear field has been found to be in rough agreement with the GM spectral model [Garrett and Munk, 1972; Gregg and Kunze, 1991], so that the $\mathrm{SF}_{6}$-derived diffusivity es- 

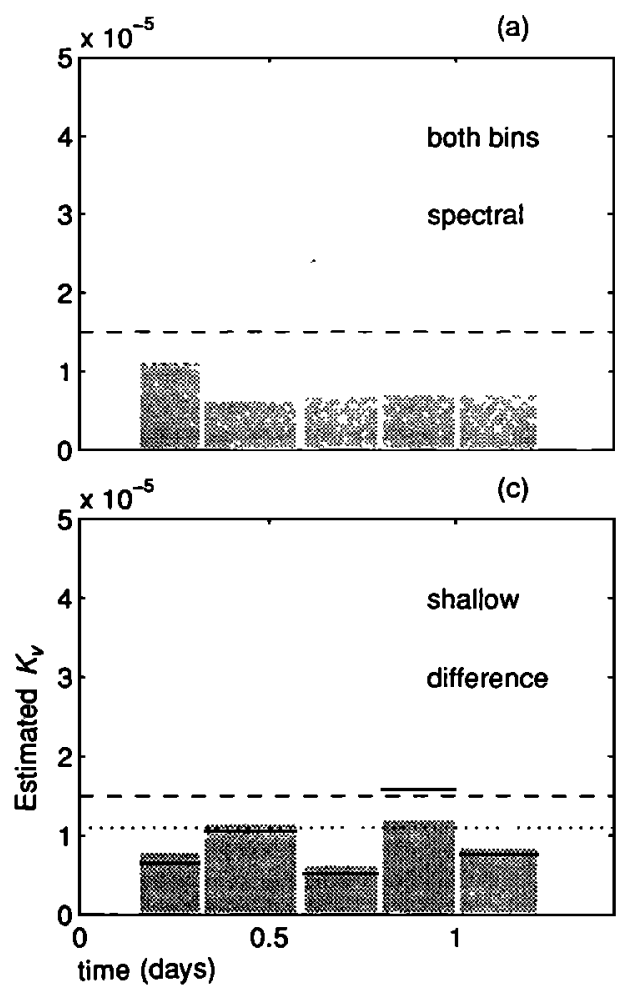

NATRE A

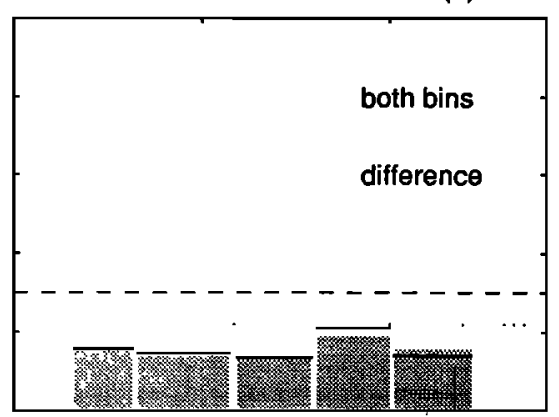

(d)

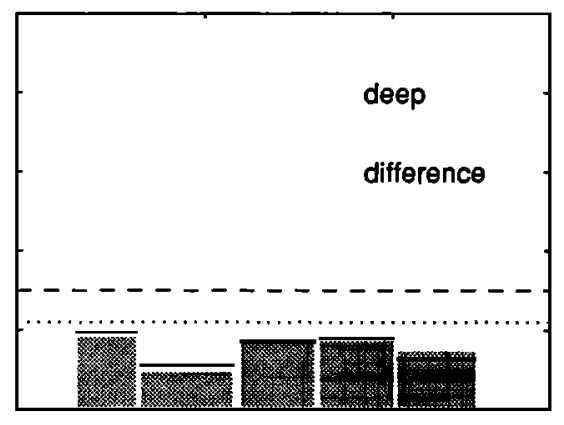

Figure 12. Estimated diffusivities $K_{v}$ from the set $\mathbf{A}$ shear groups are shown, calculated three different ways. The dotted lines show the summer 1992 diffusivity estimated from $\mathrm{SF}_{6}$ sampling. The dashed lines show the 1-year $\mathrm{SF}_{6}$-estimated diffusivity. (a) The bars indicate $K_{v}$ for the depth intervals of Figure 7, estimated using the spectral second-moment (technique 1). The bar widths indicate the temporal sampling intervals. (b) These are $K_{v}$ estimates derived from $10-\mathrm{m}$ velocity difference shear over the same depth intervals. The bars show $K_{v}$ using the secondmoment method (technique 2), the short horizontal lines near the bars indicate $K_{v}$ using the fourth-moment method (technique 3). (c) The 10-m difference estimates, calculated as in Figure $12 \mathrm{~b}$, are shown, using only data from the upper halves of the depth intervals used in Figures 12a and 12b. (d) This is as in Figure 12c, except showing difference shear from lower halves.
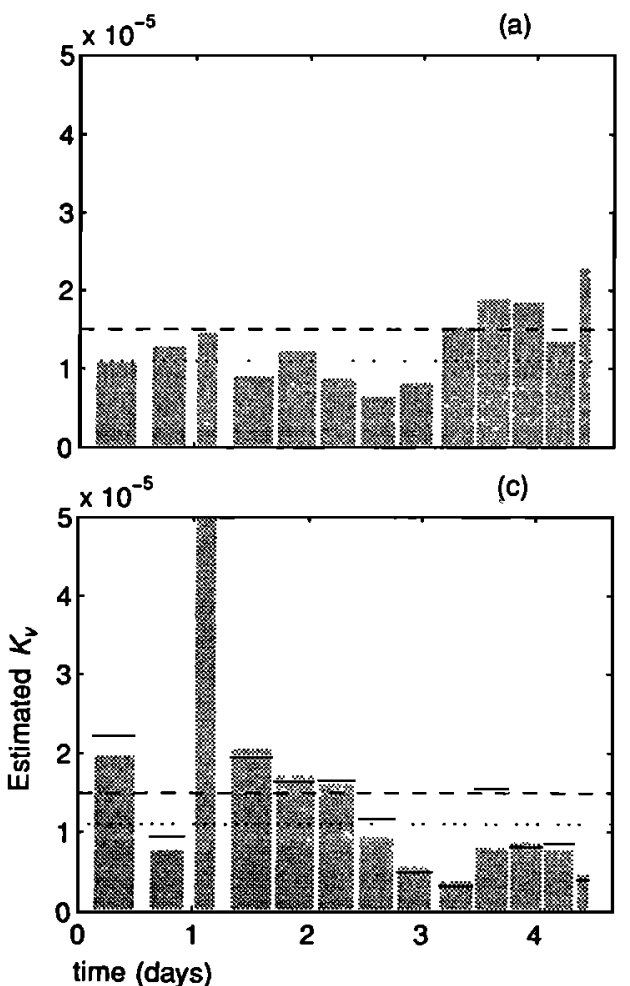

NATRE B

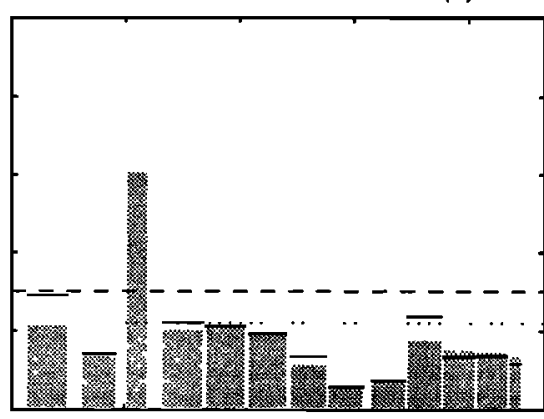

(d)

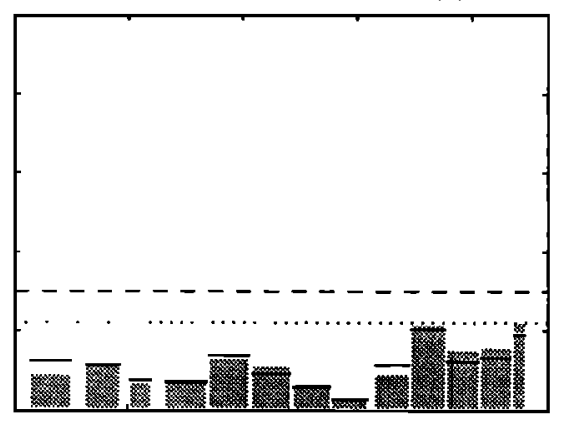

Figure 13. Similar to Figure 12, showing estimated diffusivity from data set $\mathbf{B}$. A large fourthmoment value that is off scale in Figure $13 \mathrm{~b}$ is $1.9 \times 10^{-4} \mathrm{~m}^{2} \mathrm{~s}^{-1}$. Off-scale values in Figure $13 \mathrm{c}$ are $8.3 \times 10^{-5} \mathrm{~m}^{2} \mathrm{~s}^{-1}$ (second moment) and $3.8 \times 10^{-4} \mathrm{~m}^{2} \mathrm{~s}^{-1}$ (fourth moment). 

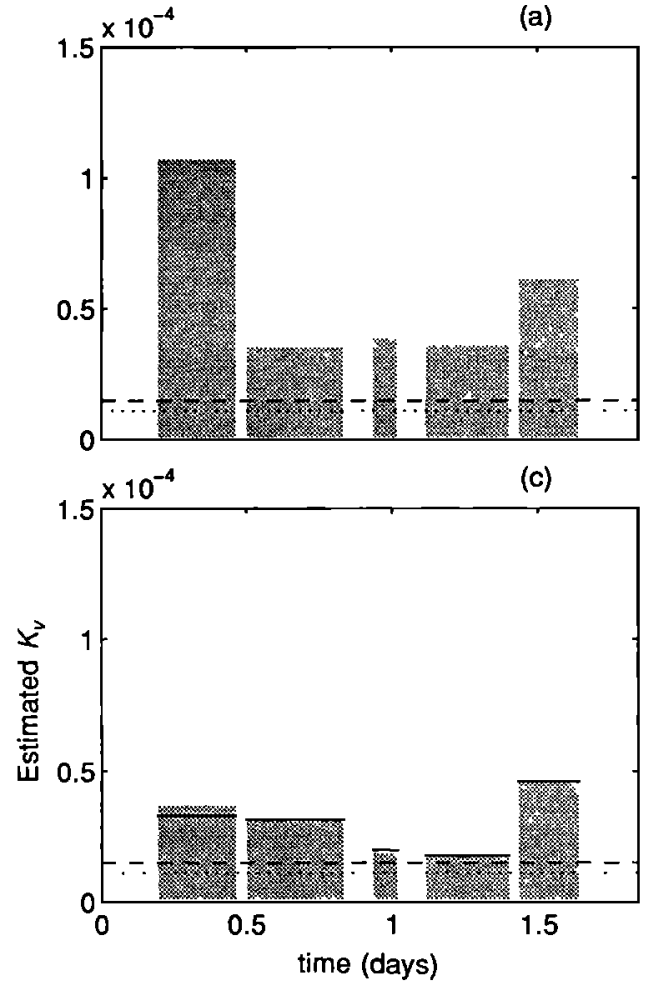

NATRE C

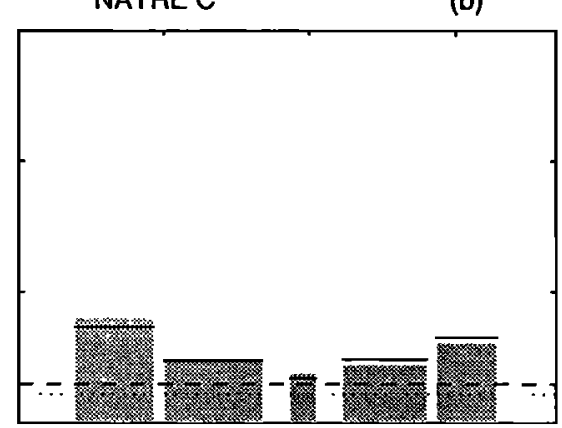

(d)

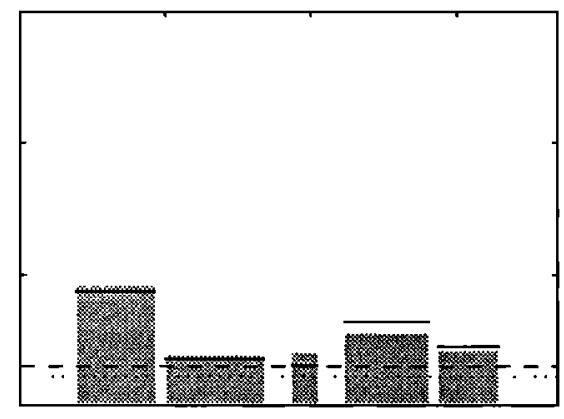

Figure 14. Similar to Figure 12, showing estimated diffusivity from data set C.

timates [Ledwell et al., 1993] are directly comparable to microstructure-based open-ocean mixing estimates collected under GM-type shear conditions. The observed shear was not precisely GM, however. Shear variance was about 2.1 times GM (average over all data), although it was very close to GM for some profile groups
(B8, B9, D5). Fall 1992 shear was about 1.6 times GM, whereas spring 1993 shear was about 2.5 to 3.0 times GM. Shear variance from a few profiles in spring 1992 was approximately double GM at the same depths in the NATRE area [Toole et at., 1994; Polzin et al., 1995].

A consequence of observed shear in excess of GM is
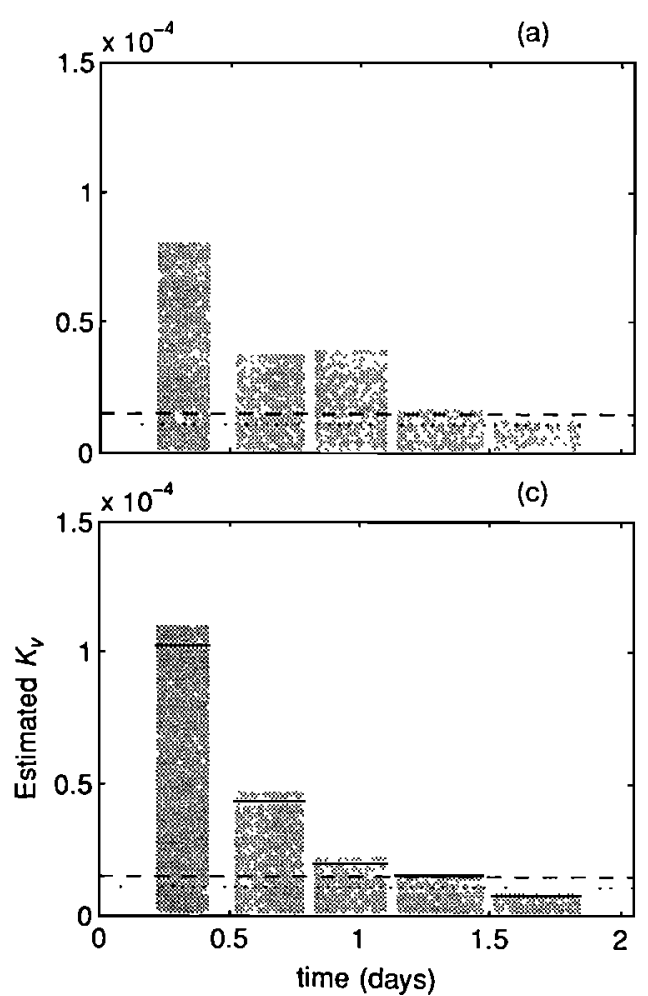

(b)

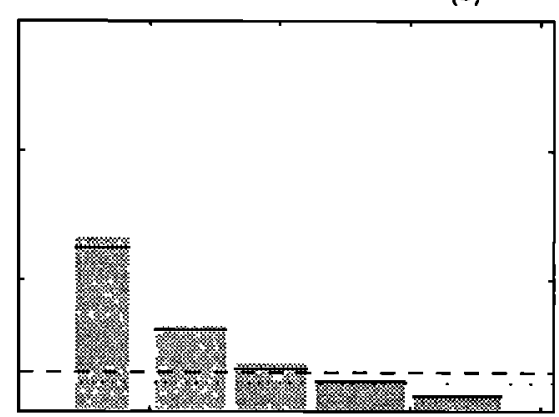

(d)

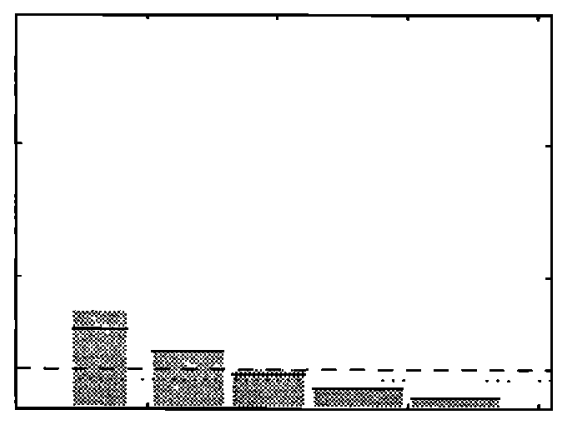

Figure 15. Similar to Figure 12, showing estimated diffusivity from data set D. The decreasing shear throughout the record gives decreasing mixing estimates. 
Table 2. Summary of Estimated $K_{v}$ from Parameterizations (7) and (8), Techniques 1-3, Not Including the Factor $X$

\begin{tabular}{cccc}
\hline Set & Technique 1 & Technique 2 & Technique 3 \\
\hline A & 0.8 & 0.8 & 0.8 \\
B & 1.3 & 0.9 & 1.7 \\
C & 5.7 & 2.9 & 2.8 \\
D & 3.4 & 2.4 & 2.3 \\
Arithmetic mean & 2.8 & 1.8 & 1.9 \\
\hline
\end{tabular}

Units are $10^{-5} \mathrm{~m}^{2} \mathrm{~s}^{-1}$. Ledwell et al. [1993] values are 1.1 for the summer and 1.5 for the year.

that predictions of eddy diffusivity from shear-based parameterizations of internal-wave decay, without the correction factor $X$, are slightly greater than the diffusivity observed with the $\mathrm{SF}_{6}$ tracer (Tables 2 and 3 ). As a check on our procedures, the parameterized diffusivity has been calculated three ways, which show good agreement. If one considers the parameterizations as upper bound inequalities, subject to uncertainties of mixing efficiency in stratified turbulence, the agreement between the two types of data is complete, mathematically, and the mixing efficiency can be estimated. Using the estimate of $1.8 \times 10^{-5} \mathrm{~m}^{2} \mathrm{~s}^{-1}$ for A-D using technique 2 , which is 1.2 times the yearlong $\mathrm{SF}_{6}$-derived estimate, an estimated efficiency from expressions (6) and (8) is $17 \%$. This is lower than typically assumed [Osborn, 1980] or found in simulations [Itsweire et al., 1993], but is greater than mixing efficiencies suggested by direct heat flux studies [Fleury and Lueck, 1994; Yamazaki and Osborn, 1993]. It is also possible that the parameterizations are not correct. This comparison of fine-scale shear to tracer diffusion skips the important step of evaluating the relation of shear to turbulent kinetic energy dissipation. However, this step has been addressed relatively successfully by Gregg [1989].

However, if the correction factor $X$ is included, then the estimated diffusivities $K_{v c}$ are lower than the tracer estimates, so that low mixing efficiency is not implied. Instead, the fact that the tracer diffusivity exceeds the shear-parameterized estimates implies that doublediffusive processes are contributing to mixing. The experiment was in a water mass with density ratio favorable to salt fingering [Turner, 1973]. Density ratios less than 2 are commonly observed, with both temperature and salinity decreasing with depth. Salt fingers have been observed in the NATRE SF $_{6}$ experiment volume (R. Schmitt, personal communication, 1994). Salt fingering would enhance diffusion beyond that caused by wave-induced turbulence. If $X$ is included, this study would then be consistent with turbulent mixing efficiencies equal to or exceeding $20 \%$, plus additional saltfinger flux.

A third situation is the combination of the non- $X$ parameterization and the hypothesis that salt fingers contribute flux. The implied mixing efficiency would than be further reduced below the already low estimate of $17 \%$ for no finger flux and no $X$ correction. The NATRE kinetic energy dissipation data collected by $\mathrm{N}$. Oakey may prove helpful in the determination of mixing efficiency, the role of salt fingers, and the choice of parameterization.

A shortcoming of this mean-shear to mean-mixing (NATRE $K_{v}$ ) comparison is that it cannot address the possibility that both shear and eddy diffusivity have seasonal cycles or other forms of variability. The observed shear from the 28 groups of profiles, which sample about 8 hours each, is variable at timescales ranging from hours to months, and shear may be variable at periods of weeks. The finite sampling means that uncertainty of shear variance is roughly the same magnitude as the observed variations at periods of hours, so these are difficult to interpret. On the other hand, the spring 1993 shear excess over fall 1992 is well sampled. All of the observed fluctuations can be interpreted as temporal variability, spatial variability, or both. To understand the influence of shear variability on mixing variability and mean mixing, these fluctuations must be resolved, and the sampling errors over short intervals must be reduced. If the fluctuations are real, their influence on mean mixing may be strong; the nonlinearity of the parameterizations (section 2) hints at this. With incomplete sampling or large measurement uncertainty, there is a danger that fine structure statistics derived from insufficient sampling (which we have observed to be variable in a seemingly homogeneous ocean region) may be misinterpreted. This sampling issue has been raised for shear and microstructure studies [Gibson, 1991].

This reminds us of the motivation for fine-scale mixing parameterizations. To measure mixing, direct measurements at dissipation scales are undoubtedly better. We see from our shear profiles, plentiful though they are, that fine structure sampling suffers from the same problems as microstructure sampling, so the substitution of shear data is not a panacea, nor was it expected to be. It is apparent that the major value of a mixing parameterization concept, which these data support, would be to link major ocean bathymetric, circulation, or forcing features, and their implicit induced fine structures, to the resultant turbulent mixing.

Table 3. Summary of Estimated $K_{v c}$ From Parameterizations (7) and (8), Techniques 1-3, Including the Factor $X$

\begin{tabular}{cccc}
\hline Set & Technique 1 & Technique 2 & Technique 3 \\
\hline A & 0.3 & 0.3 & 0.3 \\
B & 0.5 & 0.4 & 0.4 \\
C & 1.6 & 0.8 & 0.8 \\
D & 1.3 & 0.9 & 0.8 \\
Arithmetic mean & 0.9 & 0.6 & 0.6 \\
\hline
\end{tabular}

Units are $10^{-5} \mathrm{~m}^{2} \mathrm{~s}^{-1}$. Ledwell et al. [1993] values are 1.1 for the summer and 1.5 for the year. 
Table 4. Summary of Diffusivity Estimates From Second-Moment Techniques 1 and 2

\begin{tabular}{|c|c|c|c|c|c|}
\hline \multirow{2}{*}{ Set } & \multirow{2}{*}{ Group } & \multicolumn{2}{|c|}{ Technique 1} & \multicolumn{2}{|c|}{ Technique 2} \\
\hline & & $K_{v}$ & $K_{v c}$ & $K_{v}$ & $K_{v c}$ \\
\hline \multirow[t]{6}{*}{ A } & 1 & 1.12 & 0.38 & 0.84 & 0.29 \\
\hline & 2 & 0.64 & 0.28 & 0.71 & 0.31 \\
\hline & 3 & 0.70 & 0.26 & 0.73 & 0.28 \\
\hline & 4 & 0.72 & 0.28 & 0.96 & 0.37 \\
\hline & 5 & 0.73 & 0.34 & 0.79 & 0.37 \\
\hline & Weighted mean & 0.78 & 0.31 & 0.81 & 0.32 \\
\hline \multirow[t]{14}{*}{ B } & 1 & 1.09 & 0.38 & 1.08 & 0.38 \\
\hline & 2 & 1.29 & 0.65 & 0.68 & 0.34 \\
\hline & 3 & 1.47 & - & 3.04 & - \\
\hline & 4 & 0.91 & - & 1.03 & - \\
\hline & 5 & 1.24 & - & 1.07 & - \\
\hline & 6 & 0.88 & - & 0.97 & - \\
\hline & 7 & 0.65 & - & 0.58 & - \\
\hline & 8 & 0.83 & - & 0.32 & - \\
\hline & 9 & 1.54 & - & 0.40 & - \\
\hline & 10 & 1.90 & - & 0.89 & - \\
\hline & 11 & 1.87 & - & 0.78 & - \\
\hline & 12 & 1.37 & - & 0.76 & - \\
\hline & 13 & 2.30 & - & 0.69 & - \\
\hline & Weighted mean & 1.27 & 0.50 & 0.89 & 0.36 \\
\hline \multirow[t]{6}{*}{$\mathrm{C}$} & 1 & 10.7 & 2.79 & 4.03 & 1.05 \\
\hline & 2 & 3.59 & 1.40 & 2.52 & 0.98 \\
\hline & 3 & 3.89 & 0.89 & 1.92 & 0.44 \\
\hline & 4 & 3.63 & 0.94 & 2.25 & 0.58 \\
\hline & 5 & 6.15 & 1.59 & 3.10 & 0.81 \\
\hline & Weighted mean & 5.71 & 1.60 & 2.85 & 0.83 \\
\hline \multirow[t]{6}{*}{ D } & 1 & 8.04 & 2.25 & 6.66 & 1.86 \\
\hline & 2 & 3.79 & 1.52 & 3.28 & 1.31 \\
\hline & 3 & 3.97 & 1.71 & 1.86 & 0.80 \\
\hline & 4 & 1.73 & 0.69 & 1.19 & 0.47 \\
\hline & 5 & 1.34 & 0.58 & 0.65 & 0.28 \\
\hline & Weighted mean & 3.44 & 1.26 & 2.44 & 0.87 \\
\hline
\end{tabular}

Units are $10^{-5} \mathrm{~m}^{2} \mathrm{~s}^{-1}$. $K_{v}$ does not include the $X$ factor, $K_{v c}$ does. Profile quantity in each group is used to compute a weighted mean.

Acknowledgments. This work was supported by $\mathrm{Na}$ tional Science Foundation grant OCE-9216204. James Ledwell provided the information in Figure 1. Neil Oakey was the chief scientist of both cruises, providing the CTD data and the ship track information. The crews of both vessels played an essential role in deploying and recovering the instrument. The assistance of Jacques Lemire at Scripps was essential. S. Wetzel computed the displacements. Assistance at sea from B. Guest, B. Ruddick, D. Walsh, N. Kalyaniwalla, R. Hudson, D. Newman, R. Ryan, L. Petrie, and E. Verge is appreciated. Neil Oakey and James Ledwell were extremely cooperative in the integration of these measurements into the NATRE study. This is WHOI contribution number 8777 .

\section{References}

Armi, L., Some evidence for boundary mixing in the deep ocean, J. Geophys. Res., 83, 1971-1979, 1978.

Desaubies, Y., and W. K. Smith, Statistics of Richardson number and instability in oceanic internal waves, J. Phys. Oceanogr., 12, 1245-1259, 1982.

Duda, T. F., and C. S. Cox, Quasi-Lagrangian measurements of microstructure and shear near a front in the coastal California thermocline, Univ. of Calif., San Diego, SIO Ref. 88-15, La Jolla, 1988.

Duda, T. F., and C. S. Cox, Vertical wave number spectra of velocity and shear at small internal wave scales, $J$. Geophys. Res., 94, 939-950, 1989.

Duda, T. F., C. S. Cox, and T. K. Deaton, The Cartesian Diver: A self-profiling Lagrangian velocity recorder, $J$. Atmos. Oceanic Technol., 5, 16-33, 1988.

Fleury, M., and R. G. Lueck, Direct heat flux estimates using a towed vehicle, J. Phys. Oceanogr., 24, 801-818, 1994.

Gargett, A. E., Do we really know how to scale the turbulent kinetic energy dissipation rate $\epsilon$ due to breaking of oceanic internal waves?, J. Geophys. Res., 95, 15,97115,974, 1990.

Gargett, A. E., and G. Holloway, Dissipation and diffusion by internal wave breaking, $J$. Mar. Res., 42, 15-27, 1984. 
Garrett, C., A stirring tale of mixing, Nature, 364, 670-671, 1993.

Garrett, C., and W. Munk, Space-time scales of internal waves, Geophys. Fluid Dyn., 2, 225-264, 1972.

Garrett, C., P. MacCready, and P. Rhines, Boundary mixing and arrested Ekman layers: Rotating stratified flow near a sloping boundary, Annu. Rev. Fluid Mech., 25, 291-323, 1993.

Gibson, C. H., Turbulence, mixing, and heat flux in the ocean main thermocline, $J$. Geophys. Res., 96, 20,40320,420, 1991.

Gregg, M. C., Diapycnal mixing in the thermocline: A review, J. Geophys Res., 92, 5249-5286, 1987.

Gregg, M. C., Scaling turbulent dissipation in the thermocline, J. Geophys. Res., 94, 9686-9698, 1989.

Gregg, M. C. and E. Kunze, Shear and strain in Santa Monica Basin, J. Geophys. Res., 96, 16,709-16,719, 1991.

Gregg, M. C., and T. B. Sanford, The dependence of turbulent dissipation on stratification in a diffusively stable thermocline, J. Geophys. Res., 93, 12,381-12,392, 1988.

Gregg, M. C., H. E. Seim, and D. B. Percival, Statistics of shear and turbulent dissipation profiles in random internal wave fields, J. Phys. Oceanogr, 23, 1777-1799, 1993.

Henyey, F. S., Scaling of internal wave model predictions for $\epsilon$, in Proc. 'Aha Huliko'a Hawailan Winter Workshop, pp. 233-236, Univ. of Hawaji at Manoa, Honolulu, 1991.

Henyey, F. S., J. Wright, and S. M. Flatté, Energy and action flux through the internal wave field: An eikonal approach, J. Geophys. Res., 91, 8487-8495, 1986.

Hogg, N., P. Biscaye, W. Gardner, and W. J. Schmitz Jr., On the transport and modification of Antarctic Bottom Water in the Vema Channel, J. Mar. Res., 40, Suppl., 231-263, 1982.

Itsweire, E. C., J. R. Koseff, D. A. Briggs, and J. H. Ferziger, Turbulence in stratified shear flows: Implications for interpreting shear-induced mixing in the ocean, $J$. Phys. Oceanogr., 23, 1508-1522, 1993.

Ivey, G. N., The role of boundary mixing in the deep ocean, J. Geophys. Res., 92, 11,873-11,878, 1987.

Jacobs, D. C., and C. S. Cox, Estimating the vertical component of water velocity from measurements collected with a free-fall vehicle, J. Atmos. Ocean. Technol., 9, 42-54, 1992.

Leaman, K. D., Observations on the vertical polarization and energy flux of near-inertial waves, J. Phys. Oceanogr., $6,894-908,1976$

Ledwell, J. R., A. J. Watson, and C. S. Law, Evidence for slow mixing across the pycnocline from an open-ocean tracer-release experiment, Nature, 364, 701-703, 1993.

Luyten, J., M. McCartney, H. Stommel, R. Dickson, and E. Gmitrowicz, On the sources of North Atlantic Deep Water, J. Phys. Oceanogr., 23, 1885-1892, 1993.

McComas, C. H., and P. Müller, The dynamic balance of internal waves, J. Phys. Oceanogr., 11, 970-986, 1981.
Moum, J. N., and T. R. Osborn, Mixing in the main thermocline, J. Phys. Oceanogr., 16, 1250-1259, 1986.

Munk, W., Abyssal recipes, Deep Sea Res., 13, 707-730, 1966.

Munk, W. H., Internal waves and small-scale processes, in Evolution of Physical Oceanography, Scientific Surveys in Honor of Henry Stommel, edited by B. A. Warren and C. Wunsch, pp. 264-291, MIT Press, Cambridge, Mass., 1981.

Osborn, T. R., Estimates of the local rate of vertical diffusion from dissipation measurements, J. Phys. Oceanogr., 10, 83-89, 1980.

Pinkel, R., Doppler sonar observations of internal waves: The wavenumber-frequency spectrum, J. Phys. Oceanogr., 14, 1249-1270, 1984.

Pinkel, R., A Wavenumber-frequency spectrum of upper ocean shear, J. Phys. Oceanogr., 15, 1453-1469, 1985.

Pinkel, R., and S. Anderson, Toward a statistical description of finescale strain in the thermocline, J. Phys. Oceanogr., 22, 773-795, 1992.

Polzin, K. L., J. M. Toole, and R. W. Schmitt, Finescale parameterizations of turbulent dissipation, J. Phys. Oceanogr., 25, 306-328, 1995.

Toole, J. M., K. L. Polzin, and R. W. Schmitt, Estimates of diapycnal mixing in the abyssal ocean, Science, 264, 1120-1123, 1994.

Turner, J. S., Buoyancy Effects in Fluids, Cambridge Univ. Press, New York, 1973.

Whitehead, J. A., Jr., On the ratio of the mixing coefficients of heat and salt of Antarctic Bottom Water in the North Atlantic, J. Geophys. Res., 92, 2981-2984, 1987.

Whitehead, J. A., Jr., and L. V. Worthington, The flux and mixing rates of Antarctic Bottom Water within the North Atlantic, J. Geophys. Res., 87 , 7903-7924, 1982.

Yamazaki, H., and T. Osborn, Direct estimation of heat flux in a seasonal thermocline, J. Phys. Oceanogr., 23, 503516,1993 .

T. F. Duda, Bigelow 202, Applied Ocean Physics and Engineering Department, Woods Hole Oceanographic Institution, Woods Hole, MA 02543-1053. (e-mail tduda@whoi.edu)

D. C. Jacobs, Scripps Institution of Oceanography, University of California, San Diego, La Jolla, CA 92093-0230. (e-mail djacobs@ucsd.edu)

(Received August 1, 1994; revised March 23, 1995; accepted March 23, 1995.) 